\title{
Probing Molecular Interactions within Class II MHC A $/$ Glycopeptide/T-Cell Receptor Complexes Associated with Collagen-Induced Arthritis
}

\author{
Ida E. Andersson, ${ }^{\dagger}$ Balik Dzhambazov, ${ }^{\dagger}$ Rikard Holmdahl,${ }^{\ddagger}$ Anna Linusson, ${ }^{\dagger *}$ and Jan Kihlberg ${ }^{\dagger, \$, *}$ \\ ${ }^{\dagger}$ Department of Chemistry, Umeå University, SE-901 87 Umeå, Sweden \\ ${ }^{\ddagger}$ Medical Inflammation Research, BMC I11, Lund University, SE-221 84 Lund, Sweden \\ § AstraZeneca R\&D Mölndal, SE-431 83 Mölndal, Sweden \\ E-mail: anna.linusson@chem.umu.se,jan.kihlberg@chem.umu.se
}

\section{Table of Contents}

S2: Alignment of the $\mathrm{A}^{\mathrm{q}}$ and $\mathrm{A}^{\mathrm{b}}$ sequences

S2: Ramachandran and Chi plots for the $\mathrm{A}^{\mathrm{q}}$ comparative model

S3: Modified experimental procedures for preparation of GalHyl building block

S4: ${ }^{1} \mathrm{H}$ NMR chemical shifts for byproduct 35

S4: HPLC purity of backbone-modified glycopeptides

S5-S7: HPLC chromatograms for the backbone-modified glycopeptides

S8: Inhibition data for glycopeptide binding to $\mathrm{A}^{\mathrm{q}}$

S9-S10: T-cell response data

S11-S12: Dose-response curves for the T-cell responses

S13-S44: ${ }^{1} \mathrm{H}$ and ${ }^{13} \mathrm{C}$ NMR spectra 
HA2Q QGGLQNIATGKHNLGGWTKRSNFTPATNEAPQATVFPKSPVLLGQPNTLICFVDNIFPPV

1MUJ_A QGGLQNIAVVKHNLGVLTKRSNSTPATNEAPQATVFPKSPVLLGQPNTLICFVDNIFPPV

$* * * * * * * . * * * * * * * * * * * * * * * * * * * * * * * * * * * * * * * * * * * * * * * * * * * * * * *$

HA2Q INITWLRNSKSVTDGVYETSFLVNRDHSFHKLSYLTFIPSDDDIYDCKVEHWGLDEPVLKHWE

1MUJ_A

\section{INITWLRNSKSVADGVYETSFFVNRDYSFHKLSYLTFIPSDDDIYDCKVEHWGLEEPVLKHWS}

Figure S1. Alignment of the $\alpha$ chains of the class II MHC molecules $\mathrm{A}^{\mathrm{q}}$ and $\mathrm{A}^{\mathrm{b}}$.

\begin{tabular}{|c|c|}
\hline HB2Q & SERHFVAQLKGECYFTNGTQRIRSVNRYIYN \\
\hline 1MUJ_B & $\begin{array}{l}\text { SERHFVYQFMGECYFTNGTQRIRYVTRYIYN } \\
* * * * * * *: * * * * * * * * * * * * * . * * * * *\end{array}$ \\
\hline HB2Q & REEWVRFDSDVGEYRAVTELGRPDAEYWNSQPEILERTRAEVDTVCRHNYEGVETHTSLR \\
\hline 1MUJ_B & $\begin{array}{l}\text { REEYVRYDSDVGEHRAVTELGRPDAEYWNSQPEILERTRAELDTVCRHNYEGPETHTSLR } \\
* * *: * *: * * * * * *: * * * * * * * * * * * * * * * * * * * * * * * * * *: * * * * * * * * * * * * * * * * *\end{array}$ \\
\hline HB2Q & RLEQPNVAISLSRTEALNHHNTLVCSVTDFYPAKIKVRWFRNGQEETVGVSSTQLIRNGD \\
\hline 1MUJ_B & $\begin{array}{l}\text { RLEQPNVVISLS---- }- \text { HNTLVCSVTDFYPAKIKVRWFRNGQEETVGVSSTQLIRNGD } \\
* * * * * * * . * * * * \\
* * * * * * * * * * * * * * * * * * * * * * * * * * * * * * * * * * * * *\end{array}$ \\
\hline HB2Q & WTFQVLVMLEMTPHQGEVYTCHVEHPSLKSPITVEWRAQS \\
\hline 1MUJ_B & $\begin{array}{l}\text { WTFQVLVMLEMTPRRGEVYTCHVEHPSLKSPITVEWSSAE } \\
* * * * * * * * * * * *:: * * * * * * * * * * * * * * * * * * * *: .\end{array}$ \\
\hline
\end{tabular}

Figure S2. Alignment of the $\beta$ chains of the class II MHC molecules $A^{\mathrm{q}}$ and $\mathrm{A}^{\mathrm{b}}$. The seven amino acids in the $\beta$ chain of $A^{b}$ that lacked coordinates in the crystal structure (PDB code: 1MUJ) are indicated with -.

a)

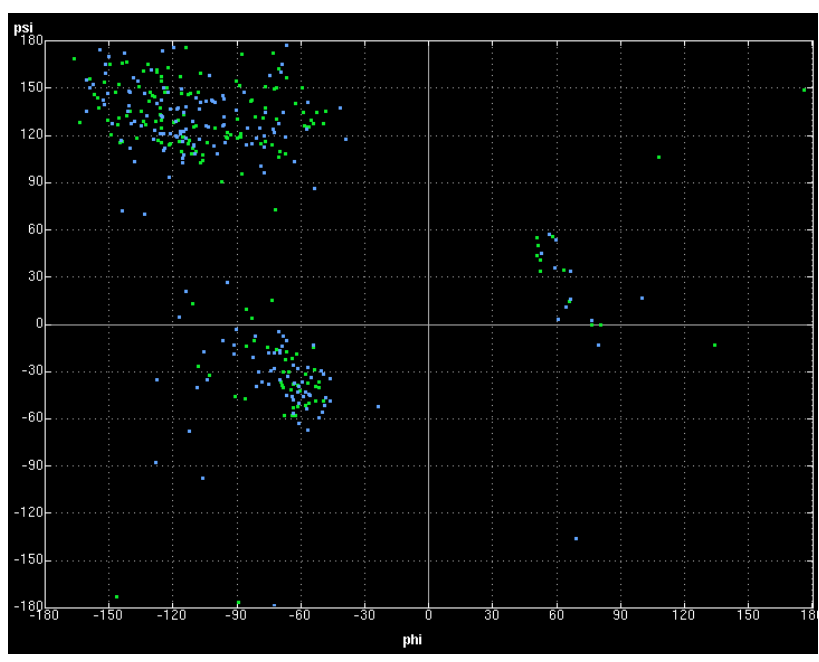

b)

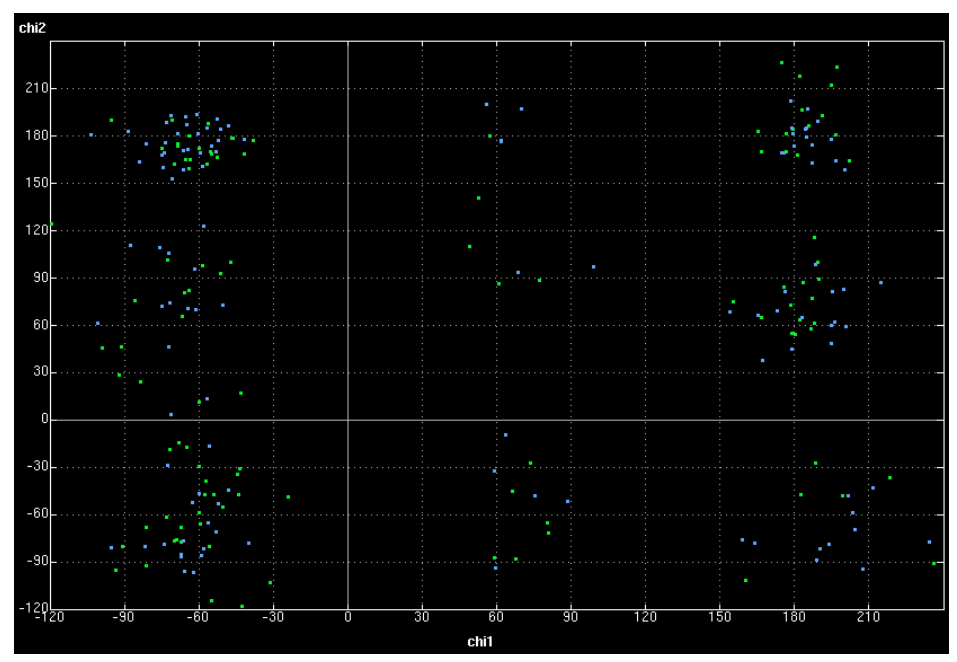

Figure S3. a) Ramachandran plot showing the phi versus psi angles of the amino acid residues in the $A^{q}$ comparative model. The $\alpha$ and $\beta$ chain are represented by green and blue dots, respectively, while outliers are represented as red crosses. b) Chi plot showing the chi1 versus chi2 angles of the amino acid residues in the $\mathrm{A}^{\mathrm{q}}$ comparative model. The $\alpha$ and $\beta$ chain are represented by green and blue dots, respectively, while outliers are represented as red crosses. 


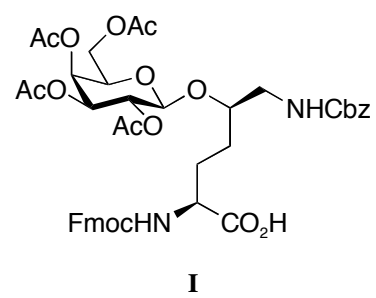

$(5 R)$ - $N^{\alpha}$-(Fluoren-9-ylmethoxycarbonyl)- $N^{\varepsilon}$-benzyloxycarbonyl-5- $O$ - $(2,3,4,6$-tetra- $O$-acetyl- $\beta$-Dgalactopyranosyl)-5-hydroxy-L-lysine (I) was synthesized from (5R)-5-hydroxy-L-lysine dihydrochloride in five steps according to a published procedure ${ }^{1}$ with the following modifications:

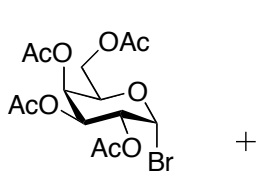

II

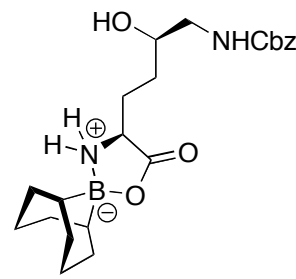

III

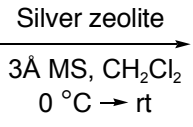

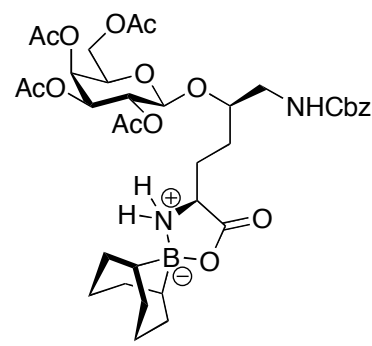

IV

(5R)- $N^{\varepsilon}$-Benzyloxycarbonyl-5- $O$-(2,3,4,6-tetra- $O$-acetyl- $\beta$-D-galactopyranosyl)-5-hydroxy-Llysinatobicyclononylboron (IV) Glycosylation of boroxazolidinone complex III was performed with silver zeolite $(2.5 \mathrm{~g} / \mathrm{mmol}$ glycosyl acceptor) as promotor. The granular silver zeolite was first grounded into a fine powder, oven dried in absence of light overnight and then allowed to cool to rt under high vacuum before being used in the reaction. The reaction mixture, which initially was cooled to $0{ }^{\circ} \mathrm{C}$, was allowed to reach rt overnight. Crude $\beta$-glycoside IV was purified by preparative HPLC on a C8 column $\left(200 \times 50 \mathrm{~mm}\right.$ ) using acetonitrile $/ \mathrm{H}_{2} \mathrm{O} /$ formic acid 59:41:0.1 as eluent, a flow rate of $118 \mathrm{~mL} / \mathrm{min}$ and detection at $210 \mathrm{~nm}$. The sample was dissolved in $\mathrm{MeOH}(250 \mathrm{mg} / \mathrm{mL})$ and $5 \mathrm{~mL}(1.25 \mathrm{~g})$ could be loaded on the column at each injection.
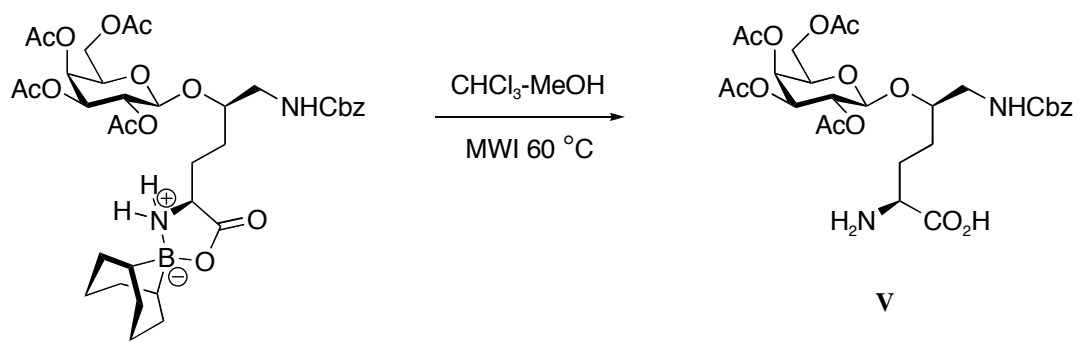

IV

(5R)- $N^{\alpha}$-(Fluoren-9-ylmethoxycarbonyl)- $N^{\varepsilon}$-benzyloxycarbonyl-5- $O$-(2,3,4,6-tetra- $O$-acetyl- $\beta$-Dgalactopyranosyl)-5-hydroxy-L-lysine (V) Borane complex IV (504 mg, $0.68 \mathrm{mmol}$ ) was dissolved in $\mathrm{MeOH}(1.6 \mathrm{~mL})$ and $\mathrm{CHCl}_{3}(10 \mathrm{~mL})$ was added followed by heating for $90 \mathrm{~min}$ at $60{ }^{\circ} \mathrm{C}$ in a closed vessle using microwave irradiation. The solution was concentrated, redissolved in $\mathrm{MeOH}(1.6 \mathrm{~mL})$ and $\mathrm{CHCl}_{3}(10 \mathrm{~mL})$, and again heated for $90 \mathrm{~min}$. This procedure was repeated until complete deprotection was achieved (three more times). The solution was concentrated and the residue was then triturated with hot hexanes followed by $\mathrm{Et}_{2} \mathrm{O}$, and finally dried under high vacuum.

1. Syed, B. M.; Gustafsson, T.; Kihlberg, J. 9-BBN as a Convenient Protecting Group in Functionalisation of Hydroxylysine. Tetrahedron 2004, 60, 5571-5575. 


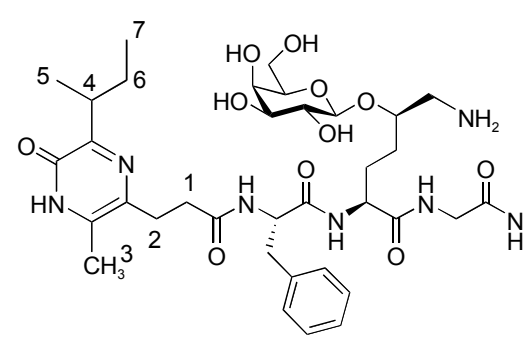

35
MS (MALDI-TOF) calcd 1005.5

$[\mathrm{M}+\mathrm{H}]^{+}$, found 1005.6.

Table S1. ${ }^{1} \mathrm{H}$ NMR chemical shifts for $35{ }^{a}$

\begin{tabular}{|c|c|c|c|c|c|}
\hline Residue & $\mathrm{NH}$ & $\mathrm{H} \alpha$ & $\mathrm{H} \beta$ & $\mathrm{H} \gamma$ & Others \\
\hline $\mathrm{N}$-terminal part & & & & & $\begin{array}{l}3.06(4), 2.84(2), 2.70(2), 2.54^{b} \\
(1), 2.09(3), 1.64(6), 1.50(6), \\
1.09(5), 0.78(7)\end{array}$ \\
\hline $\mathrm{Phe}^{263}$ & 7.96 & 4.54 & $3.06,2.82$ & & $7.12(\mathrm{H} \delta), 7.25(\mathrm{H} \varepsilon$ and $\mathrm{H} \zeta)$ \\
\hline $\mathrm{Hyl}^{264}$ & 8.44 & 4.27 & $2.01,1.76$ & $1.63^{b}$ & $4.03(\mathrm{H} \delta), 3.18$ and $2.99(\mathrm{H} \varepsilon),^{c}$ \\
\hline Gly $^{265}$ & 8.13 & $3.94,3.87$ & & & \\
\hline $\mathrm{Glu}^{266}$ & 8.21 & 4.34 & $2.10,1.93$ & $2.45^{b}$ & \\
\hline $\mathrm{Gln}^{267}$ & 8.43 & 4.27 & $2.09,1.95$ & $2.33^{b}$ & 7.55 and $7.07\left(\delta \mathrm{NH}_{2}\right),{ }^{d}$ \\
\hline
\end{tabular}

${ }^{a}$ Measured at $500 \mathrm{MHz}$ and $298 \mathrm{~K}$ in water containing $10 \% \mathrm{D}_{2} \mathrm{O}$ with $\mathrm{H}_{2} \mathrm{O}\left(\delta_{\mathrm{H}} 4.76 \mathrm{ppm}\right)$ as internal standard. ${ }^{b}$ Degeneracy has been assumed. ${ }^{c}$ Chemical shifts for the galactose moiety: $\delta=4.45$ (H1), 3.90 (H4), 3.75 (H6), 3.68 (H5), 3.63 (H3) and $3.52(\mathrm{H} 2) .{ }^{d}$ Chemical shifts for the $C$-terminal amide: $\delta=7.46,6.81$.

Table S2. HPLC purity of backbone-modified glycopeptides

\begin{tabular}{cc}
\hline \multicolumn{1}{c}{ Glycopeptide } & HPLC purity (\%) \\
\hline $\mathbf{2 8}\left(\mathrm{CII} 260-267 \mathrm{GalHyl}^{264} \mathrm{Ala}^{261} \psi\left[\mathrm{COCH}_{2}\right] \mathrm{Gly}^{262}\right)$ & 98 \\
$\mathbf{2 9}\left(\mathrm{CII} 260-267 \mathrm{GalHyl}^{264} \mathrm{Ala}^{261} \psi\left[\mathrm{CH}_{2} \mathrm{NH}_{2}{ }^{+}\right] \mathrm{Gly}^{262}\right)$ & $>99$ \\
$\mathbf{3 1}\left(\mathrm{CI} 259-273 \mathrm{GalHyl}^{264} \mathrm{Ala}^{261} \psi\left[\mathrm{COCH}_{2}\right] \mathrm{Gly}^{262}\right)$ & 98 \\
$\mathbf{3 2}\left(\mathrm{CII} 259-273 \mathrm{GalHyl}^{264} \mathrm{Ala}^{261} \psi\left[\mathrm{CH}_{2} \mathrm{NH}_{2}{ }^{+}\right] \mathrm{Gly}^{262}\right)$ & 100 \\
$\mathbf{3 3}\left(\mathrm{CII} 259-273 \mathrm{GalHyl}^{264} \mathrm{Ala}^{261} \psi[(E)-\mathrm{CH}=\mathrm{CH}] \mathrm{Gly}^{262}\right)$ & $>99$ \\
$\mathbf{3 4}\left(\mathrm{CII} 259-273 \mathrm{GalHyl}^{264} \mathrm{Ala}^{261} \psi[(\mathrm{Z})-\mathrm{CH}=\mathrm{CH}] \mathrm{Gly}^{262}\right)$ & 98 \\
\hline
\end{tabular}


Figure S4. HPLC chromatograms for 28:
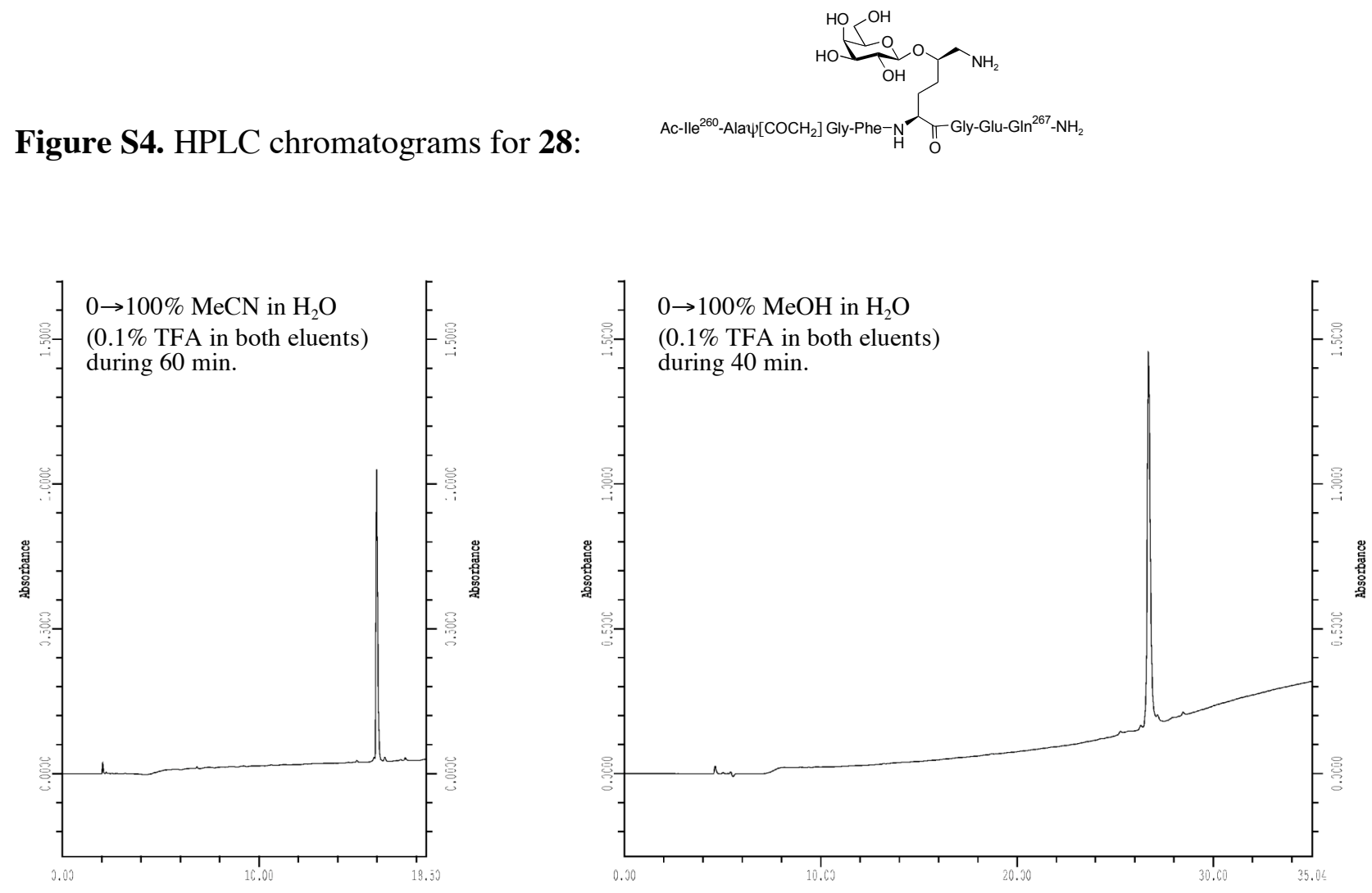

Figure S5. HPLC chromatograms for 29:
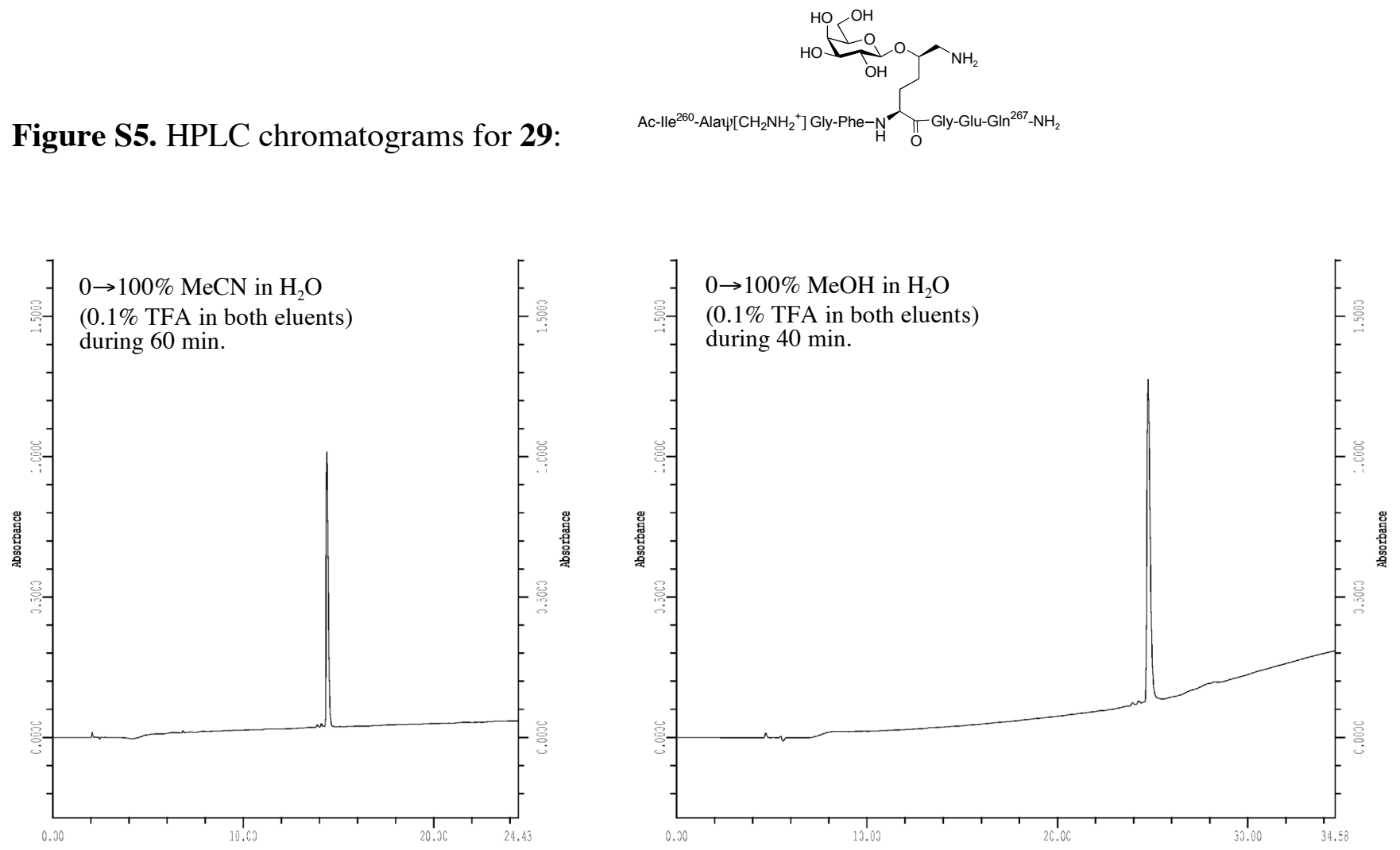
Figure S6. HPLC chromatograms for 31:

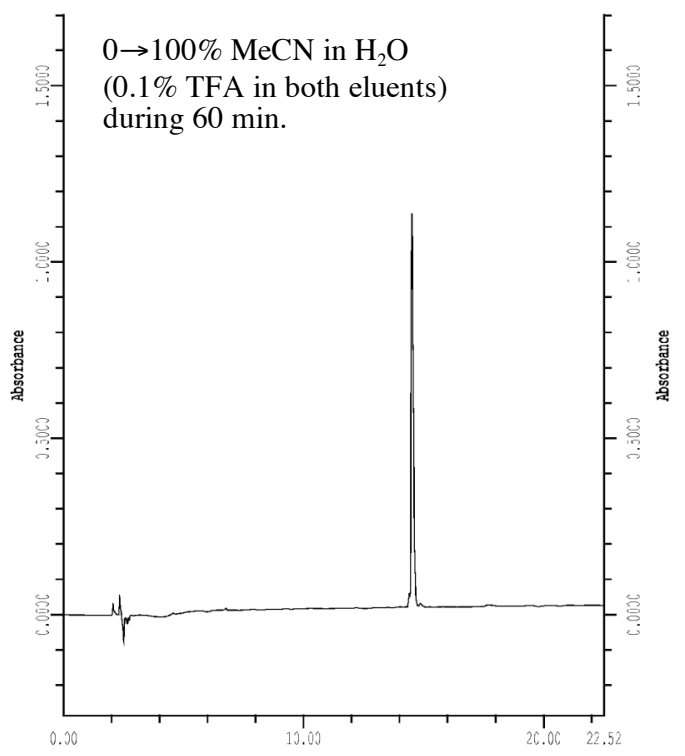

Figure S7. HPLC chromatograms for 32:

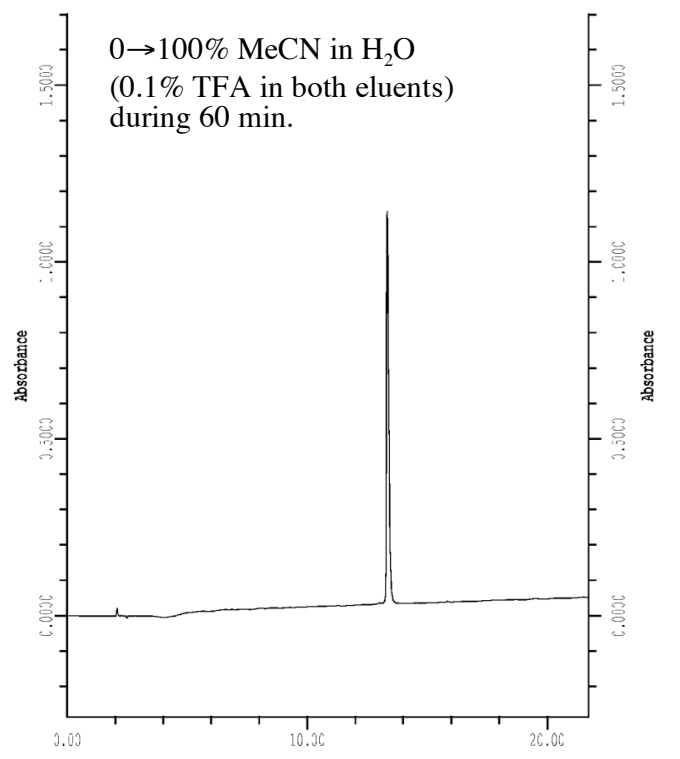

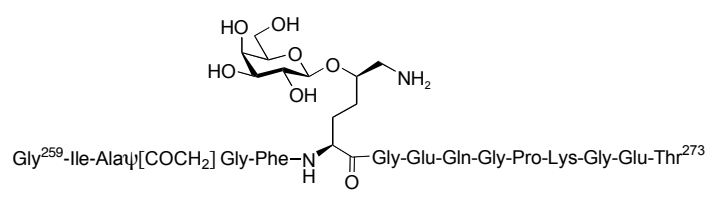
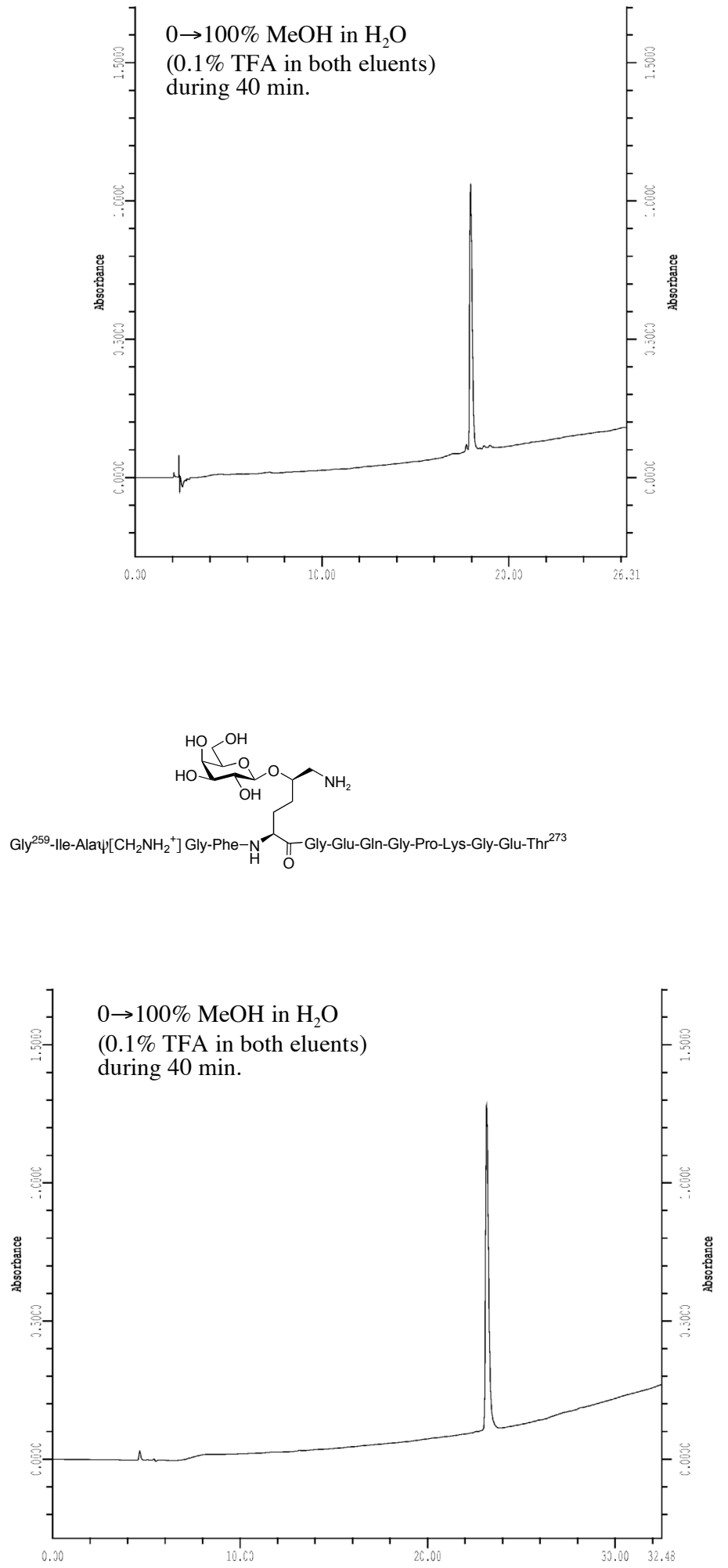
Figure S8. HPLC chromatograms for 33:

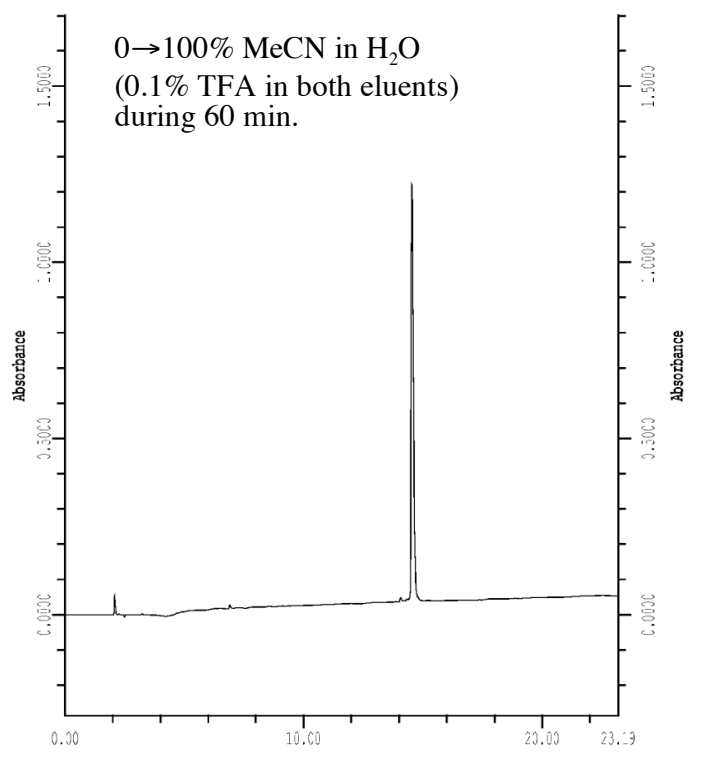

Figure S9. HPLC chromatograms for 34:

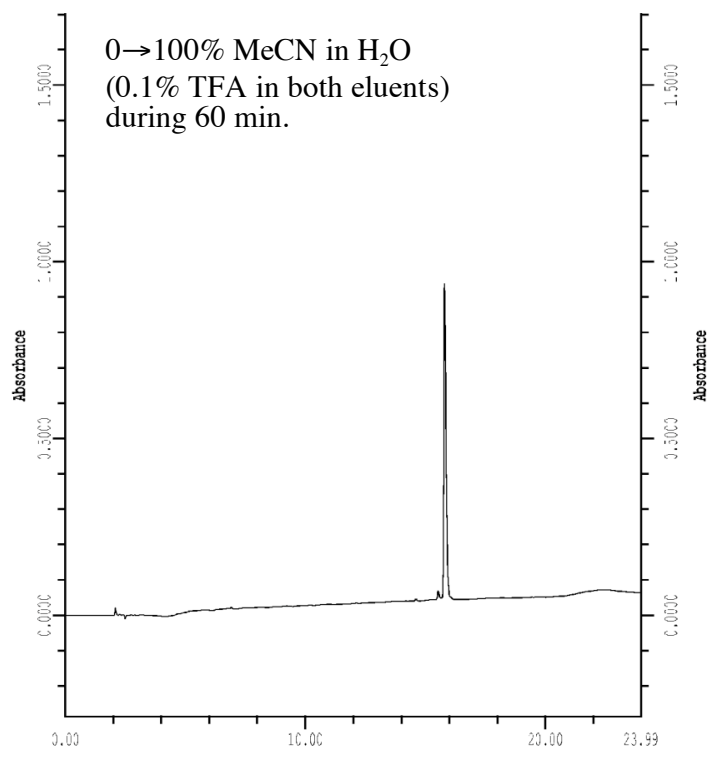

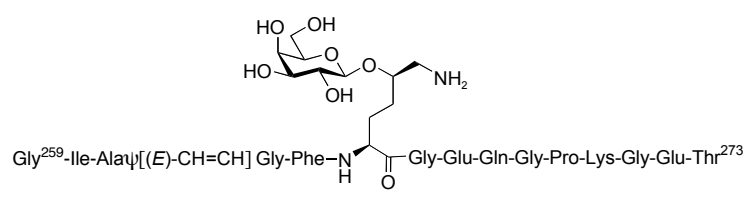
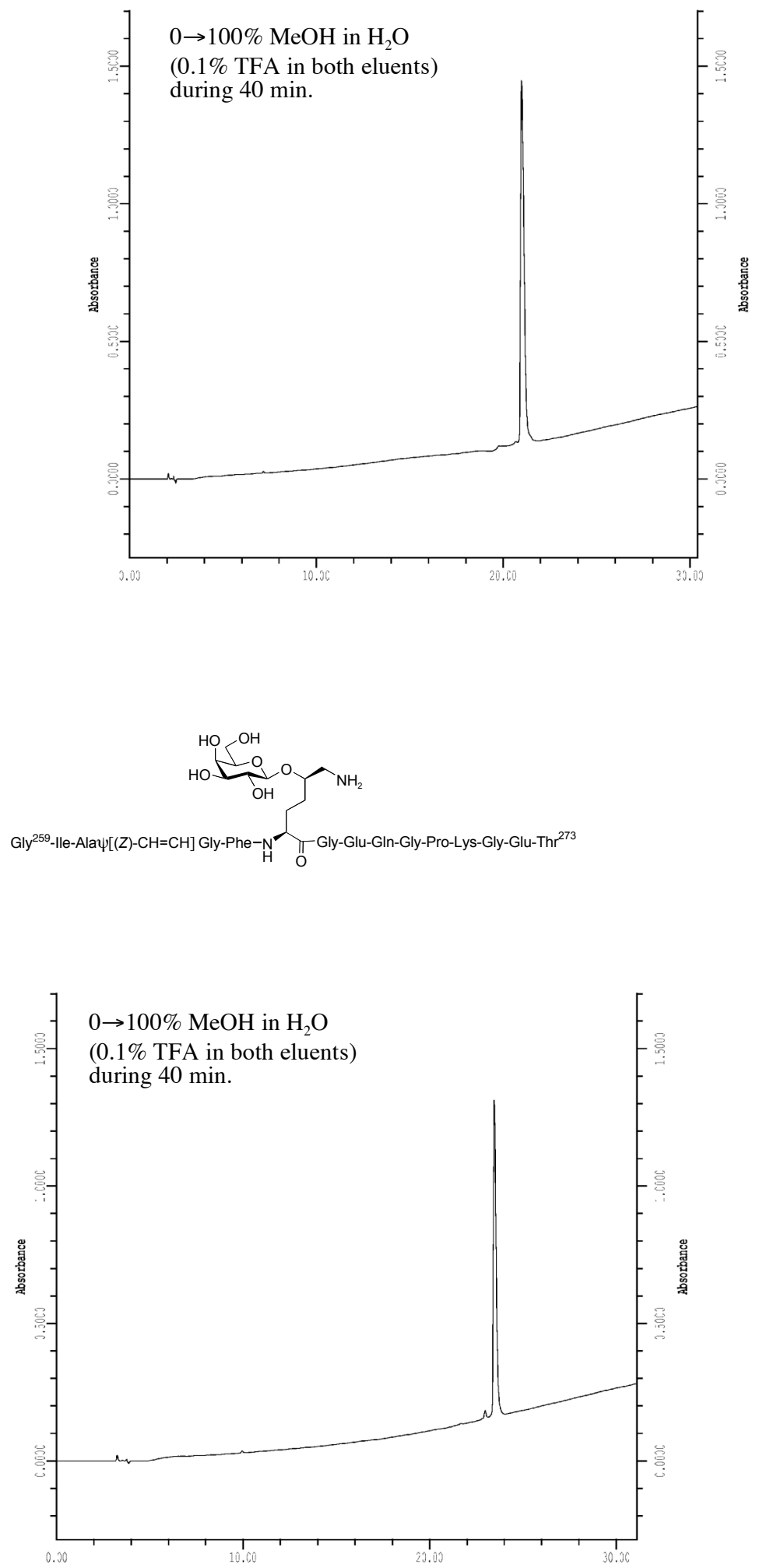
Table S3. Inhibition of binding of a fixed concentration of biotinylated CLIP peptide to the recombinant $\mathrm{A}^{\mathrm{q}}$ molecule upon incubation with various concentrations of the backbone-modified glycopeptides (28, 29, and 31-34) and the reference glycopeptides (27 and 30). The $\mathrm{A}^{\mathrm{q}}$-bound biotinylated CLIP was detected by time-resolved fluoroimmunoassay using europium-labeled streptavidin. The measured fluorescence values for two independent concentration series are given as well as the mean fluorescence value.

\begin{tabular}{|c|c|c|c|c|c|c|}
\hline \multirow{2}{*}{$\begin{array}{c}\text { Antigen } \\
\text { concentration }(\boldsymbol{\mu M})\end{array}$} & \multicolumn{3}{|c|}{$\mathbf{3 0}(\mathrm{CONH})$} & \multicolumn{3}{c|}{$\mathbf{3 1}\left(\mathrm{COCH}_{2}\right)$} \\
\cline { 2 - 7 } & Serie 1 & Serie 2 & Average & Serie 1 & Serie 2 & Average \\
\hline $\mathbf{0}$ & 46861 & 47008 & 46935 & 47131 & 46983 & 47057 \\
\hline $\mathbf{0 . 8}$ & 37054 & 37150 & 37102 & 37025 & 36972 & 36999 \\
\hline $\mathbf{4}$ & 25381 & 25733 & 25557 & 28670 & 28002 & 28336 \\
\hline $\mathbf{2 0}$ & 15411 & 15714 & 15563 & 16338 & 16902 & 16620 \\
\hline $\mathbf{1 0}$ & 5903 & 6077 & 5990 & 5677 & 5618 & 5648 \\
\hline $\mathbf{5 0 0}$ & 3213 & 3486 & 3350 & 5920 & 5012 & 5466 \\
\hline
\end{tabular}

\begin{tabular}{|c|c|c|c|c|c|c|}
\hline \multirow{2}{*}{$\begin{array}{c}\text { Antigen } \\
\text { concentration }(\boldsymbol{\mu} \mathrm{M})\end{array}$} & \multicolumn{3}{|c|}{$\mathbf{3 2}\left(\mathrm{CH}_{2} \mathrm{NH}_{2}{ }^{+}\right)$} & \multicolumn{3}{|c|}{$\mathbf{3 3}((E)-\mathrm{CH}=\mathrm{CH}))$} \\
\cline { 2 - 7 } & Serie 1 & Serie 2 & Average & Serie 1 & Serie 2 & Average \\
\hline $\mathbf{0}$ & 47361 & 47719 & 47540 & 47541 & 48074 & 47808 \\
\hline $\mathbf{0 . 8}$ & 47674 & 46782 & 47228 & 45746 & 45596 & 45671 \\
\hline $\mathbf{4}$ & 42814 & 42884 & 42849 & 35728 & 35148 & 35438 \\
\hline $\mathbf{2 0}$ & 35744 & 36136 & 35940 & 17105 & 17130 & 17118 \\
\hline $\mathbf{1 0 0}$ & 8140 & 8391 & 8266 & 6649 & 6435 & 6542 \\
\hline $\mathbf{5 0 0}$ & 8948 & 8358 & 8653 & 6808 & 6770 & 6789 \\
\hline
\end{tabular}

\begin{tabular}{|c|c|c|c|c|c|c|}
\hline \multirow{2}{*}{$\begin{array}{c}\text { Antigen } \\
\text { concentration }(\boldsymbol{\mu M})\end{array}$} & \multicolumn{3}{|c|}{$\mathbf{3 4}((\mathrm{Z})-\mathrm{CH}=\mathrm{CH}))$} & \multicolumn{3}{c|}{$\mathbf{2 7}(\mathrm{CONH})$} \\
\cline { 2 - 7 } & Serie 1 & Serie 2 & Average & Serie 1 & Serie 2 & Average \\
\hline $\mathbf{0}$ & 47298 & 47286 & 47292 & 47975 & 47132 & 47554 \\
\hline $\mathbf{0 . 8}$ & 47008 & 46925 & 46967 & 40005 & 39727 & 39866 \\
\hline $\mathbf{4}$ & 46411 & 47499 & 46955 & 27483 & 27062 & 27273 \\
\hline $\mathbf{2 0}$ & 46216 & 45939 & 46078 & 22974 & 23364 & 23169 \\
\hline $\mathbf{1 0 0}$ & 39964 & 39439 & 39702 & 7742 & 7829 & 7786 \\
\hline $\mathbf{5 0 0}$ & 38334 & 37661 & 37998 & 4302 & 4847 & 4575 \\
\hline
\end{tabular}

\begin{tabular}{|c|c|c|c|c|c|c|}
\hline \multirow{2}{*}{$\begin{array}{c}\text { Antigen } \\
\text { concentration }(\mu \mathrm{M})\end{array}$} & \multicolumn{3}{|c|}{$28\left(\mathrm{COCH}_{2}\right)$} & \multicolumn{3}{|c|}{$29\left(\mathrm{CH}_{2} \mathrm{NH}_{2}^{+}\right)$} \\
\hline & Serie 1 & Serie 2 & Average & Serie 1 & Serie 2 & Average \\
\hline 0 & 46952 & 47191 & 47072 & 46938 & 47037 & 46988 \\
\hline 0.8 & 47487 & 46963 & 47225 & 45355 & 45496 & 45426 \\
\hline 4 & 38091 & 38044 & 38068 & 45880 & 45079 & 45480 \\
\hline 20 & 26963 & 26251 & 26607 & 36128 & 35839 & 35984 \\
\hline 100 & 18042 & 17998 & 18020 & 35883 & 36062 & 35973 \\
\hline 500 & 16654 & 16380 & 16517 & 35896 & 35328 & 35612 \\
\hline
\end{tabular}


Table S4. T-cell responses induced by the backbone-modified glycopeptides 28, 29, and 31-34 and the reference glycopeptide 30. The glycopeptides were incubated with antigen-presenting spleen cells expressing $\mathrm{A}^{\mathrm{q}}$ and each of the selected hybridomas. Recognition of the $\mathrm{A}^{\mathrm{q}} / \mathrm{glycopeptide}$ complex by a Tcell hybridoma results in secretion of interleukin-2 (IL-2) into the medium, which was quantified in an ELISA.

\begin{tabular}{|l|c|c|c|c|c|c|c|}
\hline \multicolumn{7}{|c|}{ HCQ.2 hybridoma } \\
\hline $\begin{array}{l}\text { Antigen } \\
\text { conc. }(\mu \mathrm{M})\end{array}$ & $\begin{array}{c}\mathbf{3 0} \\
(\mathrm{CONH})\end{array}$ & $\begin{array}{c}\mathbf{3 1} \\
\left(\mathrm{CHCH}_{2}\right)\end{array}$ & $\begin{array}{c}\mathbf{3 2} \\
\left(\mathrm{CH}_{2} \mathrm{NH}_{2}{ }^{+}\right)\end{array}$ & $\begin{array}{c}\mathbf{3 3} \\
((E)-\mathrm{CH}=\mathrm{CH})\end{array}$ & $\begin{array}{c}\mathbf{3 4} \\
((\mathrm{Z})-\mathrm{CH}=\mathrm{CH})\end{array}$ & $\begin{array}{c}\mathbf{2 8} \\
\left(\mathrm{COCH}_{2}\right)\end{array}$ & $\begin{array}{c}\mathbf{2 9} \\
\left(\mathrm{CH}_{2} \mathrm{NH}_{2}{ }^{+}\right)\end{array}$ \\
\hline $\mathbf{2 0}$ & 85019 & 54769 & 5885 & 15941 & 4751 & 32911 & 3463 \\
\hline $\mathbf{4}$ & 83046 & 15474 & 4267 & 4726 & 4188 & 10243 & 2828 \\
\hline $\mathbf{0 . 8}$ & 58099 & 9213 & 4102 & 2670 & 3433 & 3980 & 2765 \\
\hline $\mathbf{0 . 1 6}$ & 19889 & 3708 & 3112 & 3573 & 3112 & 2878 & 2162 \\
\hline $\mathbf{0 . 0 3 2}$ & 5618 & 3516 & 3639 & 3772 & 3791 & 2998 & 2854 \\
\hline $\mathbf{0 . 0 0 6 4}$ & 3698 & 3706 & 3582 & 3462 & 3616 & 3587 & 3245 \\
\hline $\mathbf{0 . 0 0 1 2 8}$ & 3100 & 3895 & 3784 & 3647 & 3660 & 3838 & 3070 \\
\hline Blank & 3869 & 3721 & 3878 & 3710 & 3419 & 3290 & 3620 \\
\hline
\end{tabular}

\begin{tabular}{|l|c|c|c|c|c|c|c|}
\hline \multicolumn{7}{|c|}{ HCQ.3 hybridoma } \\
\hline $\begin{array}{l}\text { Antigen } \\
\text { conc. }(\mu \mathrm{M})\end{array}$ & $\begin{array}{c}\mathbf{3 0} \\
(\mathrm{CONH})\end{array}$ & $\begin{array}{c}\mathbf{3 1} \\
\left(\mathrm{CHCH}_{2}\right)\end{array}$ & $\begin{array}{c}\mathbf{3 2} \\
\left(\mathrm{CH}_{2} \mathrm{NH}_{2}{ }^{+}\right)\end{array}$ & $\begin{array}{c}\mathbf{3 3} \\
((E)-\mathrm{CH}=\mathrm{CH})\end{array}$ & $\begin{array}{c}\mathbf{3 4} \\
((\mathrm{Z})-\mathrm{CH}=\mathrm{CH})\end{array}$ & $\begin{array}{c}\mathbf{2 8} \\
\left(\mathrm{COCH}_{2}\right)\end{array}$ & $\begin{array}{c}\mathbf{2 9} \\
\left(\mathrm{CH}_{2} \mathrm{NH}_{2}{ }^{+}\right)\end{array}$ \\
\hline $\mathbf{2 0}$ & 196730 & 120040 & 10795 & 46054 & 8852 & 116727 & 10289 \\
\hline $\mathbf{4}$ & 152169 & 68396 & 5919 & 10376 & 6404 & 42004 & 6269 \\
\hline $\mathbf{0 . 8}$ & 116267 & 26572 & 5929 & 6377 & 5159 & 10752 & 6557 \\
\hline $\mathbf{0 . 1 6}$ & 69479 & 10116 & 5803 & 5672 & 6145 & 8210 & 6340 \\
\hline $\mathbf{0 . 0 3 2}$ & 25566 & 7073 & 5437 & 6774 & 5913 & 6191 & 6272 \\
\hline $\mathbf{0 . 0 0 6 4}$ & 13549 & 6844 & 5061 & 6246 & 5570 & 6954 & 6920 \\
\hline $\mathbf{0 . 0 0 1 2 8}$ & 8332 & 5936 & 5112 & 6032 & 5572 & 6193 & 6228 \\
\hline Blank & 3022 & 3233 & 3236 & 3411 & 3399 & 3752 & 3088 \\
\hline
\end{tabular}

\begin{tabular}{|l|c|c|c|c|c|c|c|}
\hline \multicolumn{7}{|c|}{ HCQ.6 hybridoma } \\
\hline $\begin{array}{l}\text { Antigen } \\
\text { conc. }(\mu \mathrm{M})\end{array}$ & $\begin{array}{c}\mathbf{3 0} \\
(\mathrm{CONH})\end{array}$ & $\begin{array}{c}\mathbf{3 1}\left(\mathrm{CHCH}_{2}\right) \\
\mathbf{2 0}\end{array}$ & $\begin{array}{c}\mathbf{3 2} \\
\left(\mathrm{CH}_{2} \mathrm{NH}_{2}{ }^{+}\right)\end{array}$ & $\begin{array}{c}\mathbf{3 3} \\
((E)-\mathrm{CH}=\mathrm{CH})\end{array}$ & $\begin{array}{c}\mathbf{3 4} \\
((\mathrm{Z})-\mathrm{CH}=\mathrm{CH})\end{array}$ & $\begin{array}{c}\mathbf{2 8} \\
\left(\mathrm{COCH}_{2}\right)\end{array}$ & $\begin{array}{c}\mathbf{2 9} \\
\left(\mathrm{CH}_{2} \mathrm{NH}_{2}{ }^{+}\right)\end{array}$ \\
\hline $\mathbf{4}$ & 63696 & 35898 & 3934 & 14577 & 3715 & 24957 & 2818 \\
\hline $\mathbf{0 . 8}$ & 55941 & 19620 & 2492 & 3525 & 2441 & 10656 & 2027 \\
\hline $\mathbf{0 . 1 6}$ & 42707 & 7669 & 2842 & 2241 & 2121 & 3738 & 1926 \\
\hline $\mathbf{0 . 0 3 2}$ & 25058 & 2675 & 2094 & 2021 & 1949 & 2149 & 1854 \\
\hline $\mathbf{0 . 0 0 6 4}$ & 2905 & 1923 & 1882 & 1899 & 1730 & 1741 & 1754 \\
\hline $\mathbf{0 . 0 0 1 2 8}$ & 2514 & 2137 & 2544 & 2248 & 2125 & 2187 & 2092 \\
\hline Blank & 3461 & 3174 & 3632 & 3579 & 3118 & 3674 & 2113 \\
\hline
\end{tabular}

\begin{tabular}{|l|c|c|c|c|c|c|c|}
\hline \multicolumn{7}{|c|}{$\mathbf{H C Q . 1 0}$ hybridoma } \\
\hline $\begin{array}{l}\text { Antigen } \\
\text { conc. }(\boldsymbol{\mu} \mathbf{M})\end{array}$ & $\begin{array}{c}\mathbf{3 0} \\
(\mathrm{CONH})\end{array}$ & $\begin{array}{c}\mathbf{3 1} \\
\left(\mathrm{CHCH}_{2}\right)\end{array}$ & $\begin{array}{c}\mathbf{3 2} \\
\left(\mathrm{CH}_{2} \mathrm{NH}_{2}{ }^{+}\right)\end{array}$ & $\begin{array}{c}\mathbf{3 3} \\
((E)-\mathrm{CH}=\mathrm{CH})\end{array}$ & $\begin{array}{c}\mathbf{3 4} \\
((\mathrm{Z})-\mathrm{CH}=\mathrm{CH})\end{array}$ & $\begin{array}{c}\mathbf{2 8} \\
\left(\mathrm{COCH}_{2}\right)\end{array}$ & $\begin{array}{c}\mathbf{2 9} \\
\left(\mathrm{CH}_{2} \mathrm{NH}_{2}{ }^{+}\right)\end{array}$ \\
\hline $\mathbf{2 0}$ & 558793 & 5054 & 3809 & 4766 & 4316 & 7312 & 5598 \\
\hline $\mathbf{0 . 8}$ & 286887 & 5809 & 3786 & 4865 & 4650 & 5031 & 5685 \\
\hline $\mathbf{0 . 1 6}$ & 94887 & 5089 & 4577 & 5838 & 5071 & 5078 & 6017 \\
\hline $\mathbf{0 . 0 3 2}$ & 15682 & 4491 & 5119 & 4092 & 4230 & 5827 & 6479 \\
\hline $\mathbf{0 . 0 0 6 4}$ & 6341 & 4757 & 4442 & 4644 & 4864 & 5020 & 5050 \\
\hline $\mathbf{0 . 0 0 1 2 8}$ & 6434 & 4396 & 4806 & 4235 & 4544 & 5292 & 5840 \\
\hline Blank & 4951 & 4498 & 3939 & 4637 & 3834 & 4935 & 4886 \\
\hline
\end{tabular}




\begin{tabular}{|l|c|c|c|c|c|c|c|}
\hline \multicolumn{7}{|c|}{ HM1R.2 hybridoma } \\
\hline $\begin{array}{l}\text { Antigen } \\
\text { conc. }(\boldsymbol{\mu} \mathrm{M})\end{array}$ & $\begin{array}{c}\mathbf{3 0} \\
(\mathrm{CONH})\end{array}$ & $\begin{array}{c}\mathbf{3 1} \\
\left(\mathrm{CHCH}_{2}\right)\end{array}$ & $\begin{array}{c}\mathbf{3 2} \\
\left(\mathrm{CH}_{2} \mathrm{NH}_{2}{ }^{+}\right)\end{array}$ & $\begin{array}{c}\mathbf{3 3} \\
((\mathrm{E})-\mathrm{CH}=\mathrm{CH})\end{array}$ & $\begin{array}{c}\mathbf{3 4} \\
((\mathrm{Z})-\mathrm{CH}=\mathrm{CH})\end{array}$ & $\begin{array}{c}\mathbf{2 8} \\
\left(\mathrm{COCH}_{2}\right)\end{array}$ & $\begin{array}{c}\mathbf{2 9} \\
\left(\mathrm{CH}_{2} \mathrm{NH}_{2}{ }^{+}\right)\end{array}$ \\
\hline $\mathbf{2 0}$ & 258541 & 109263 & 2148 & 5862 & 2430 & 77769 & 2181 \\
\hline $\mathbf{4}$ & 167880 & 47832 & 1809 & 2404 & 1793 & 14710 & 1675 \\
\hline $\mathbf{0 . 8}$ & 46554 & 15214 & 1717 & 1877 & 1780 & 2587 & 1735 \\
\hline $\mathbf{0 . 1 6}$ & 13947 & 2710 & 1947 & 1651 & 1748 & 1937 & 1662 \\
\hline $\mathbf{0 . 0 3 2}$ & 2288 & 2003 & 1814 & 1836 & 1655 & 1692 & 1622 \\
\hline $\mathbf{0 . 0 0 6 4}$ & 1928 & 1638 & 2105 & 1867 & 1814 & 1721 & 1799 \\
\hline $\mathbf{0 . 0 0 1 2 8}$ & 2465 & 2088 & 2013 & 1858 & 1888 & 1712 & 1772 \\
\hline Blank & 2282 & 3013 & 3702 & 3179 & 2859 & 2906 & 2023 \\
\hline
\end{tabular}

\begin{tabular}{|l|c|c|c|c|c|c|c|}
\hline \multicolumn{7}{|l|}{ HD13.9 hybridoma } \\
\hline $\begin{array}{l}\text { Antigen } \\
\text { conc. }(\boldsymbol{\mu} \mathrm{M})\end{array}$ & $\begin{array}{c}\mathbf{3 0} \\
(\mathrm{CONH})\end{array}$ & $\begin{array}{c}\mathbf{3 1} \\
\left(\mathrm{CHCH}_{2}\right)\end{array}$ & $\begin{array}{c}\mathbf{3 2} \\
\left(\mathrm{CH}_{2} \mathrm{NH}_{2}{ }^{+}\right)\end{array}$ & $\begin{array}{c}\mathbf{3 3} \\
((\mathrm{E})-\mathrm{CH}=\mathrm{CH})\end{array}$ & $\begin{array}{c}\mathbf{3 4} \\
((\mathrm{Z})-\mathrm{CH}=\mathrm{CH})\end{array}$ & $\begin{array}{c}\mathbf{2 8} \\
\left(\mathrm{COCH}_{2}\right)\end{array}$ & $\begin{array}{c}\mathbf{2 9} \\
\left(\mathrm{CH}_{2} \mathrm{NH}_{2}{ }^{+}\right)\end{array}$ \\
\hline $\mathbf{2 0}$ & 41669 & 35165 & 2097 & 3072 & 2142 & 23282 & 1940 \\
\hline $\mathbf{4}$ & 25293 & 16964 & 2305 & 2061 & 2138 & 8777 & 2027 \\
\hline $\mathbf{0 . 8}$ & 11251 & 6593 & 2074 & 1848 & 2164 & 2974 & 1760 \\
\hline $\mathbf{0 . 1 6}$ & 3611 & 2607 & 2145 & 1845 & 1846 & 1603 & 1754 \\
\hline $\mathbf{0 . 0 3 2}$ & 2079 & 1784 & 1822 & 1887 & 2081 & 1821 & 1704 \\
\hline $\mathbf{0 . 0 0 6 4}$ & 1797 & 2767 & 1937 & 1746 & 1878 & 1746 & 1618 \\
\hline $\mathbf{0 . 0 0 1 2 8}$ & 1908 & 1822 & 1820 & 1834 & 1897 & 1981 & 1774 \\
\hline Blank & 2344 & 2072 & 1932 & 2236 & 2136 & 2422 & 2367 \\
\hline
\end{tabular}

\begin{tabular}{|l|c|c|c|c|c|c|c|}
\hline \multicolumn{7}{|c|}{ HD13.10 hybridoma } \\
\hline $\begin{array}{l}\text { Antigen } \\
\text { conc. }(\boldsymbol{\mu} \mathbf{M})\end{array}$ & $\begin{array}{c}\mathbf{3 0} \\
(\mathrm{CONH})\end{array}$ & $\begin{array}{c}\mathbf{3 1} \\
\left(\mathrm{CHCH}_{2}\right)\end{array}$ & $\begin{array}{c}\mathbf{3 2} \\
\left(\mathrm{CH}_{2} \mathrm{NH}_{2}{ }^{+}\right)\end{array}$ & $\begin{array}{c}\mathbf{3 3} \\
((\mathrm{E})-\mathrm{CH}=\mathrm{CH})\end{array}$ & $\begin{array}{c}\mathbf{3 4} \\
((\mathrm{Z})-\mathrm{CH}=\mathrm{CH})\end{array}$ & $\begin{array}{c}\mathbf{2 8} \\
\left(\mathrm{COCH}_{2}\right)\end{array}$ & $\begin{array}{c}\mathbf{2 9} \\
\left(\mathrm{CH}_{2} \mathrm{NH}_{2}{ }^{+}\right)\end{array}$ \\
\hline $\mathbf{2 0}$ & 31800 & 28051 & 3501 & 4249 & 2451 & 18784 & 2367 \\
\hline $\mathbf{4}$ & 20964 & 17271 & 2288 & 1815 & 1858 & 10846 & 1888 \\
\hline $\mathbf{0 . 8}$ & 10895 & 8074 & 1926 & 1953 & 1601 & 5042 & 1697 \\
\hline $\mathbf{0 . 1 6}$ & 4978 & 3167 & 1877 & 2129 & 1856 & 2327 & 1737 \\
\hline $\mathbf{0 . 0 3 2}$ & 1892 & 1720 & 1660 & 1718 & 1656 & 1885 & 1635 \\
\hline $\mathbf{0 . 0 0 6 4}$ & 1805 & 1724 & 2054 & 1698 & 1854 & 1720 & 1620 \\
\hline $\mathbf{0 . 0 0 1 2 8}$ & 2075 & 1823 & 1920 & 1969 & 1817 & 1880 & 1768 \\
\hline Blank & 3161 & 2505 & 3470 & 3135 & 2932 & 3556 & 3236 \\
\hline
\end{tabular}

\begin{tabular}{|l|c|c|c|c|c|c|c|}
\hline \multicolumn{7}{|l|}{ HNC.1 hybridoma } \\
\hline $\begin{array}{l}\text { Antigen } \\
\text { conc. }(\boldsymbol{\mu} \mathrm{M})\end{array}$ & $\begin{array}{c}\mathbf{3 0} \\
(\mathrm{CONH})\end{array}$ & $\begin{array}{c}\mathbf{3 1} \\
\left(\mathrm{CHCH}_{2}\right)\end{array}$ & $\begin{array}{c}\mathbf{3 2} \\
\left(\mathrm{CH}_{2} \mathrm{NH}_{2}{ }^{+}\right)\end{array}$ & $\begin{array}{c}\mathbf{3 3} \\
((\mathrm{E})-\mathrm{CH}=\mathrm{CH})\end{array}$ & $\begin{array}{c}\mathbf{3 4} \\
((\mathrm{Z})-\mathrm{CH}=\mathrm{CH})\end{array}$ & $\begin{array}{c}\mathbf{2 8} \\
\left(\mathrm{COCH}_{2}\right)\end{array}$ & $\begin{array}{c}\mathbf{2 9} \\
\left(\mathrm{CH}_{2} \mathrm{NH}_{2}{ }^{+}\right)\end{array}$ \\
\hline $\mathbf{4 0}$ & 25969 & 10640 & 2524 & 1563 & 2651 & 6120 & 3169 \\
\hline $\mathbf{0 . 8}$ & 18829 & 5421 & 2224 & 1945 & 2639 & 2452 & 2770 \\
\hline $\mathbf{0 . 1 6}$ & 7542 & 3875 & 2027 & 2160 & 3729 & 3461 & 3158 \\
\hline $\mathbf{0 . 0 3 2}$ & 4208 & 2027 & 2601 & 2324 & 3128 & 3310 & 3170 \\
\hline $\mathbf{0 . 0 0 6 4}$ & 3498 & 1771 & 2474 & 2469 & 1596 & 2591 & 3434 \\
\hline $\mathbf{0 . 0 0 1 2 8}$ & 2307 & 2664 & 2613 & 2569 & 2390 & 2774 & 2114 \\
\hline Blank & 1990 & 2726 & 2414 & 2012 & 2019 & 1972 & 2153 \\
\hline
\end{tabular}

\begin{tabular}{|l|c|c|c|c|c|c|c|}
\hline \multicolumn{2}{|c|}{$\mathbf{2 2 a 1 - 7 E ~ h y b r i d o m a ~}$} \\
\hline $\begin{array}{l}\text { Antigen } \\
\text { conc. }(\boldsymbol{\mu} \mathrm{M})\end{array}$ & $\begin{array}{c}\mathbf{3 0} \\
(\mathrm{CONH})\end{array}$ & $\begin{array}{c}\mathbf{3 1} \\
\left(\mathrm{CHCH}_{2}\right)\end{array}$ & $\begin{array}{c}\mathbf{3 2} \\
\left(\mathrm{CH}_{2} \mathrm{NH}_{2}{ }^{+}\right)\end{array}$ & $\begin{array}{c}\mathbf{3 3} \\
((\mathrm{E})-\mathrm{CH}=\mathrm{CH})\end{array}$ & $\begin{array}{c}\mathbf{3 4} \\
((\mathrm{Z})-\mathrm{CH}=\mathrm{CH})\end{array}$ & $\begin{array}{c}\mathbf{2 8} \\
(\mathbf{C O C H}\end{array}$ & $\begin{array}{c}\mathbf{2 9} \\
\left(\mathrm{CH}_{2} \mathrm{NH}_{2}{ }^{+}\right)\end{array}$ \\
\hline $\mathbf{4 0}$ & 37610 & 9523 & 1810 & 2439 & 2177 & 4355 & 1762 \\
\hline $\mathbf{0 . 8}$ & 20024 & 3796 & 1695 & 1380 & 1871 & 3347 & 2221 \\
\hline $\mathbf{0 . 1 6}$ & 12920 & 2093 & 2205 & 2096 & 1688 & 2046 & 2940 \\
\hline $\mathbf{0 . 0 3 2}$ & 3517 & 1638 & 1314 & 1705 & 1240 & 1289 & 1848 \\
\hline $\mathbf{0 . 0 0 6 4}$ & 1562 & 1376 & 2488 & 2096 & 1630 & 1756 & 1889 \\
\hline $\mathbf{0 . 0 0 1 2 8}$ & 1831 & 1736 & 1938 & 1796 & 2269 & 2429 & 1911 \\
\hline Blank & 1832 & 2406 & 1842 & 1952 & 2843 & 2004 & 2094 \\
\hline
\end{tabular}


Figure S10. Dose-response curves for the T-cell responses induced by modified glycopeptides 28-34 and the reference glycopeptide 30. The glycopeptides were incubated with antigen-presenting spleen cells expressing $\mathrm{A}^{\mathrm{q}}$ and each of the hybridomas. Recognition of the $\mathrm{A}^{\mathrm{q}} / \mathrm{glycopeptide}$ complex by a hybridoma results in secretion of interleukin-2 (IL-2) into the medium, which was quantified in an ELISA.

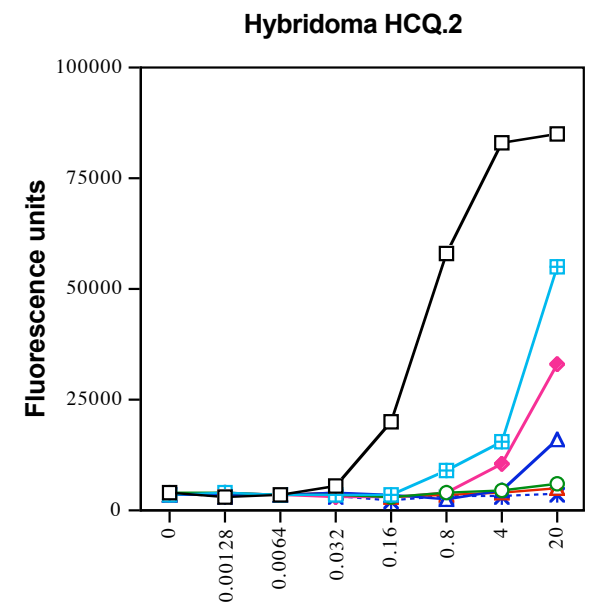

Antigen concentration $(\mu \mathrm{M})$

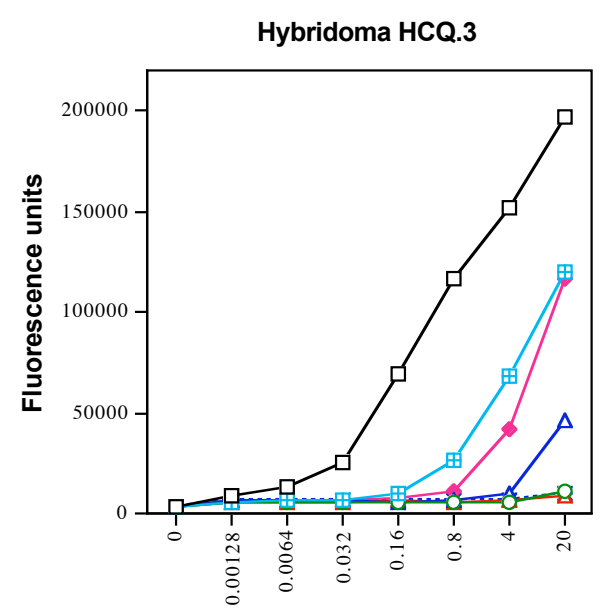

Antigen concentration $(\mu \mathrm{M})$

Hybridoma HCQ.10

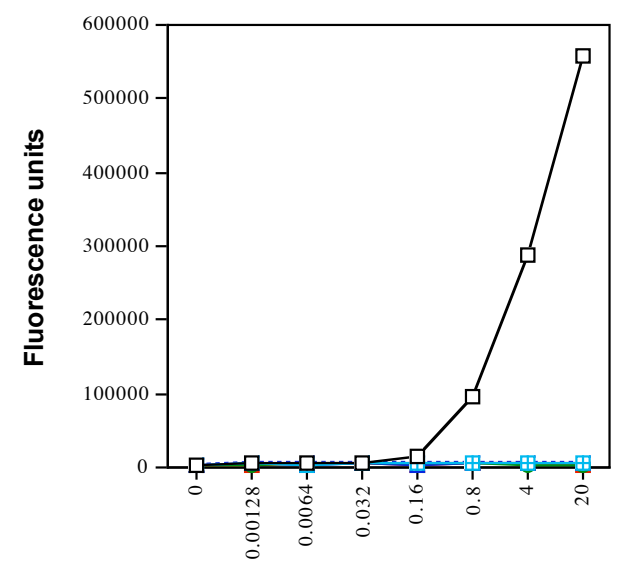

Antigen concentration $(\mu \mathrm{M})$
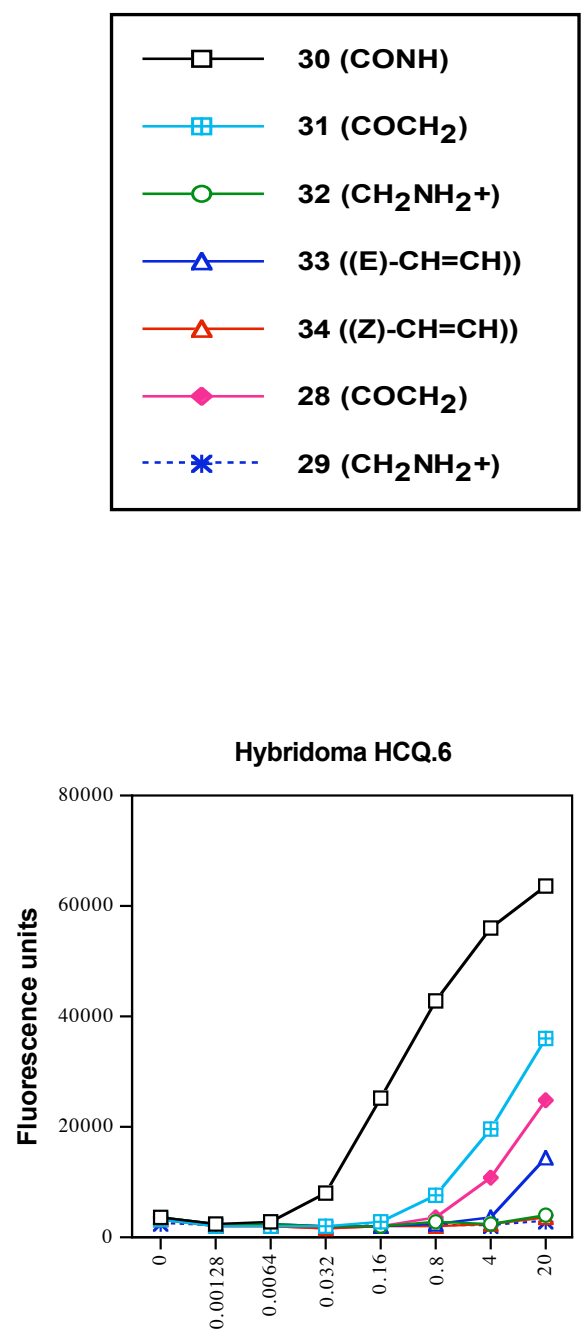

Antigen concentration $(\mu \mathrm{M})$

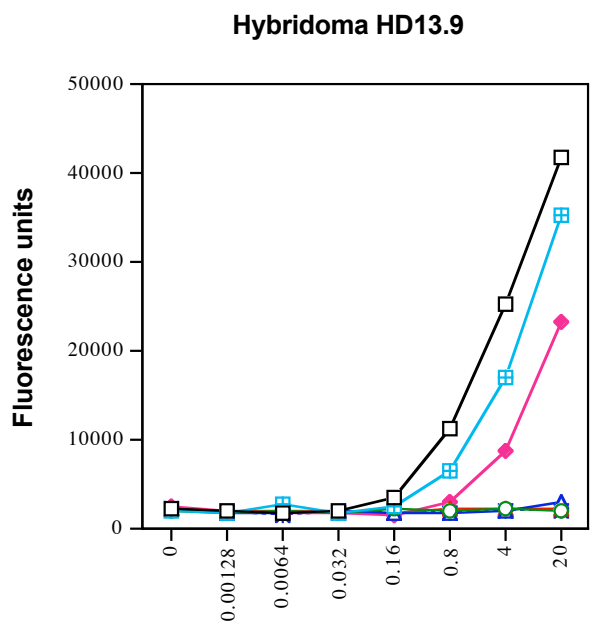

S11

Antigen concentration $(\mu \mathrm{M})$ 


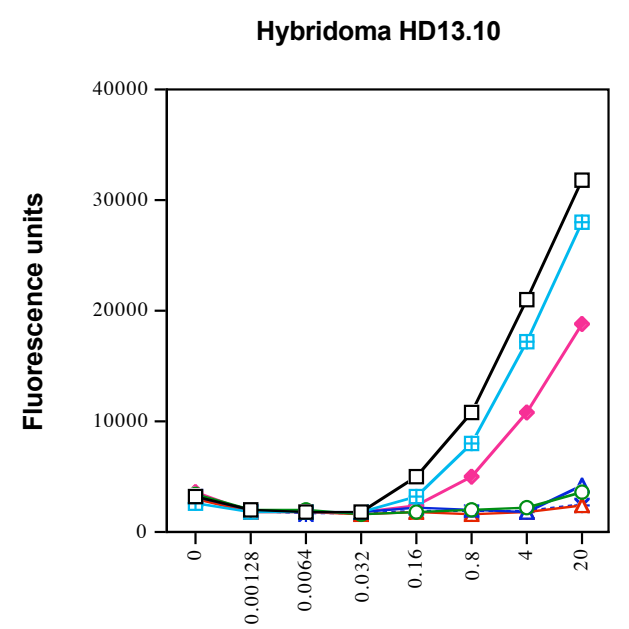

Antigen concentration ( $\mu \mathrm{M})$

Hybridoma HM1R.2

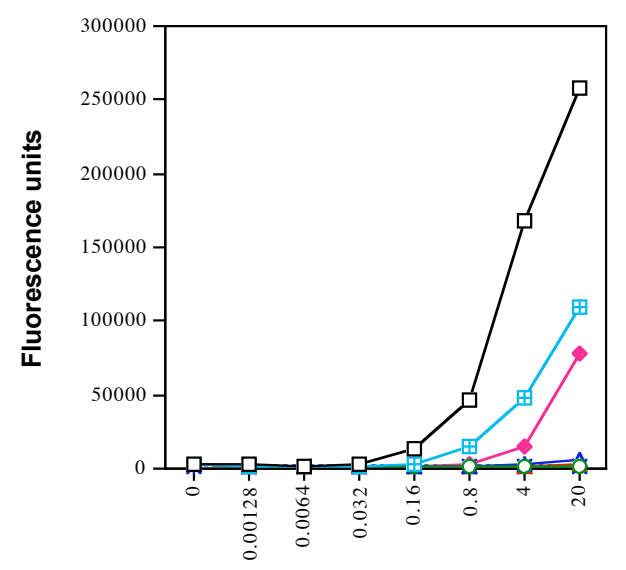

Antigen concentration ( $\mu \mathrm{M})$

Hybridoma 22a1-7E

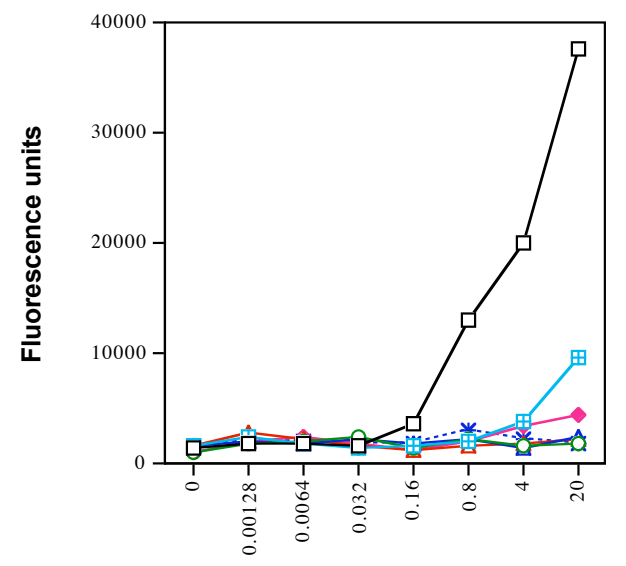

Antigen concentration $(\mu \mathrm{M})$
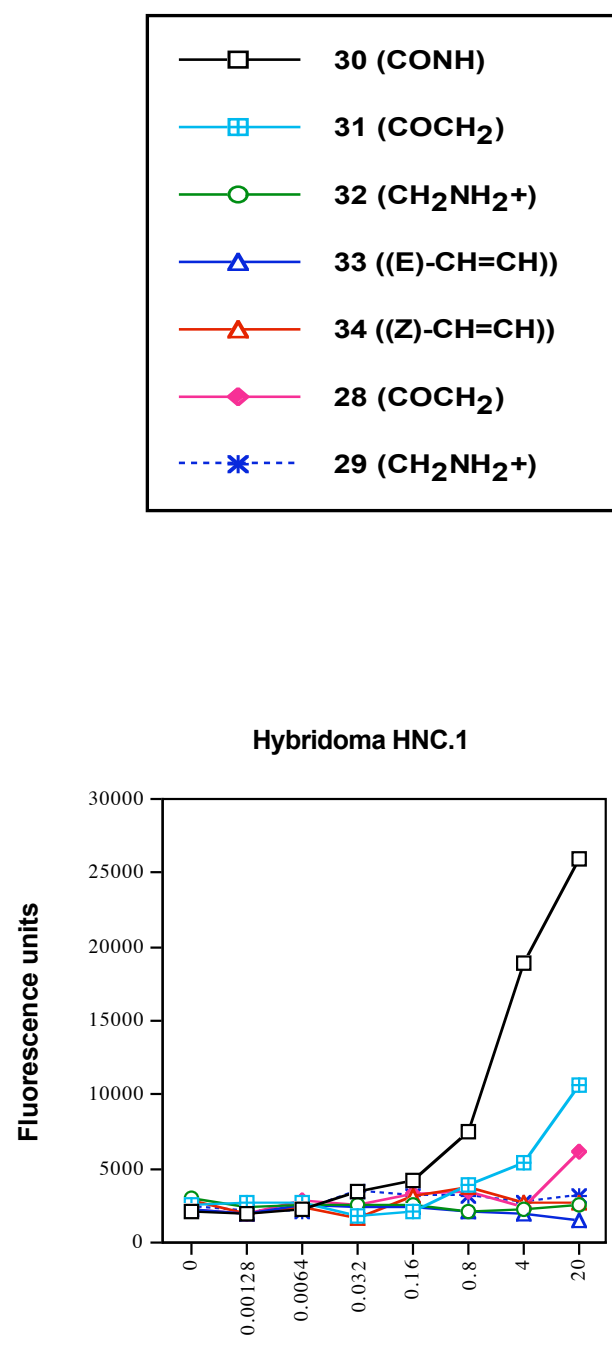

Antigen concentration ( $\mu \mathrm{M})$ 


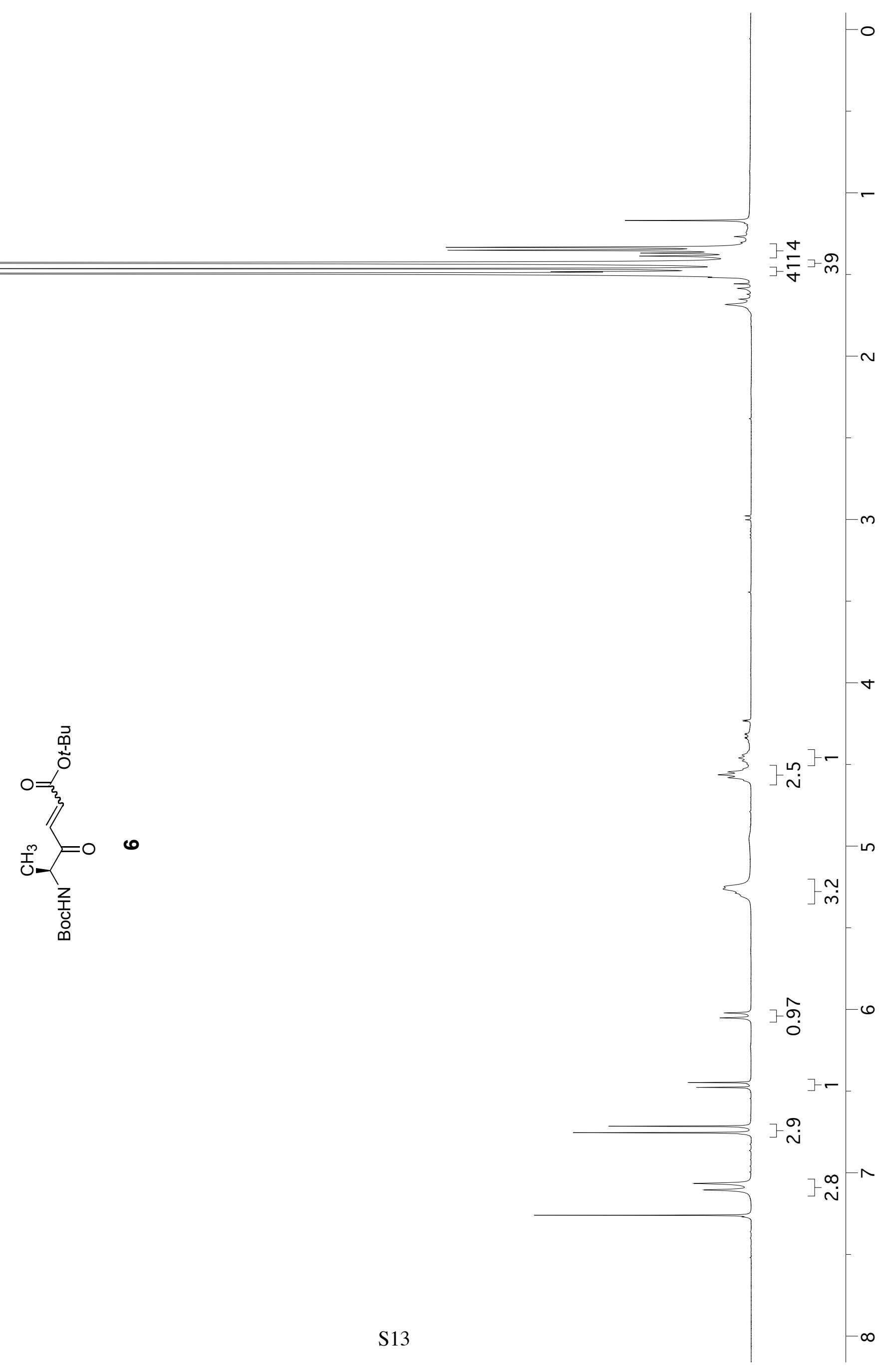




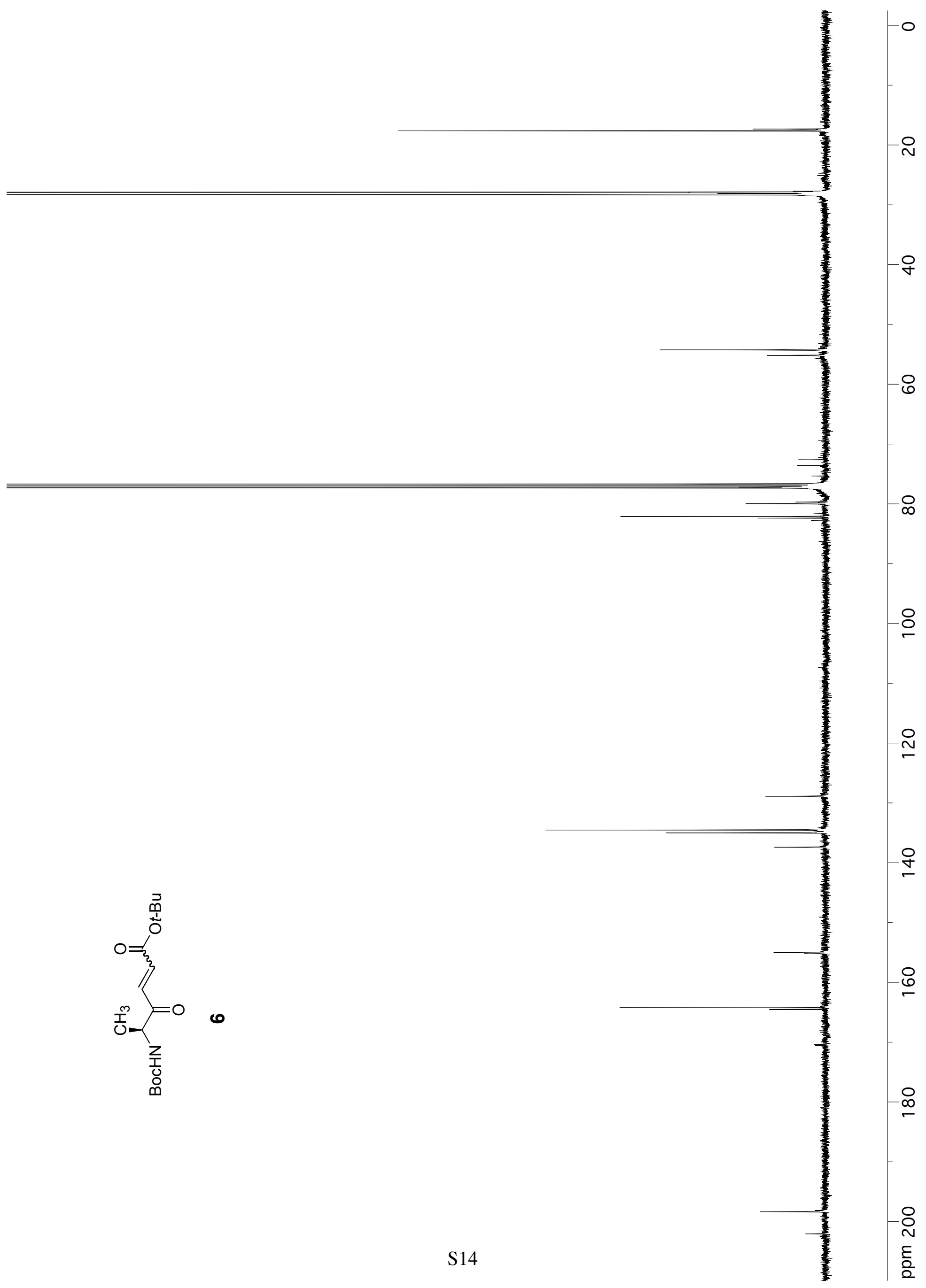




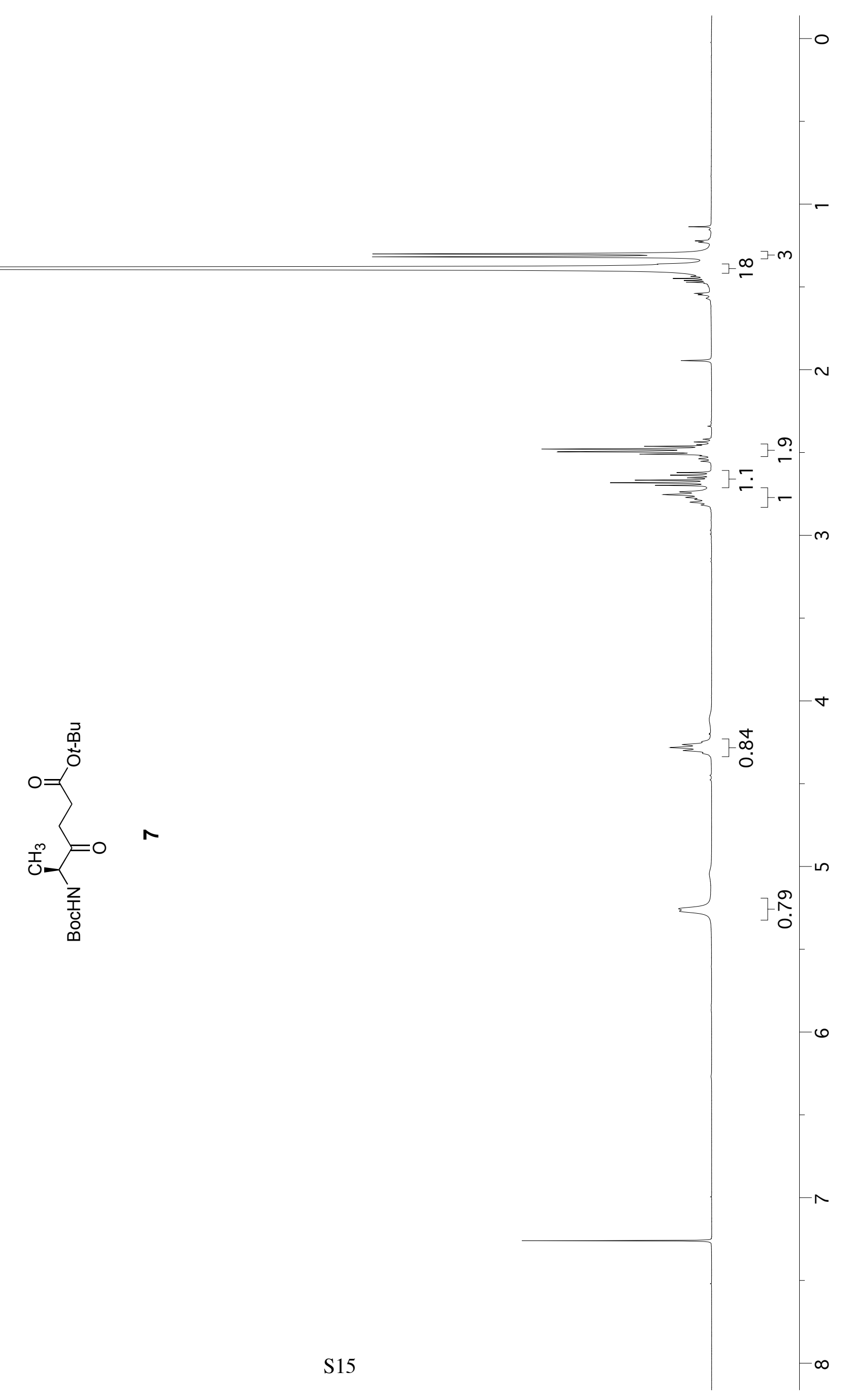




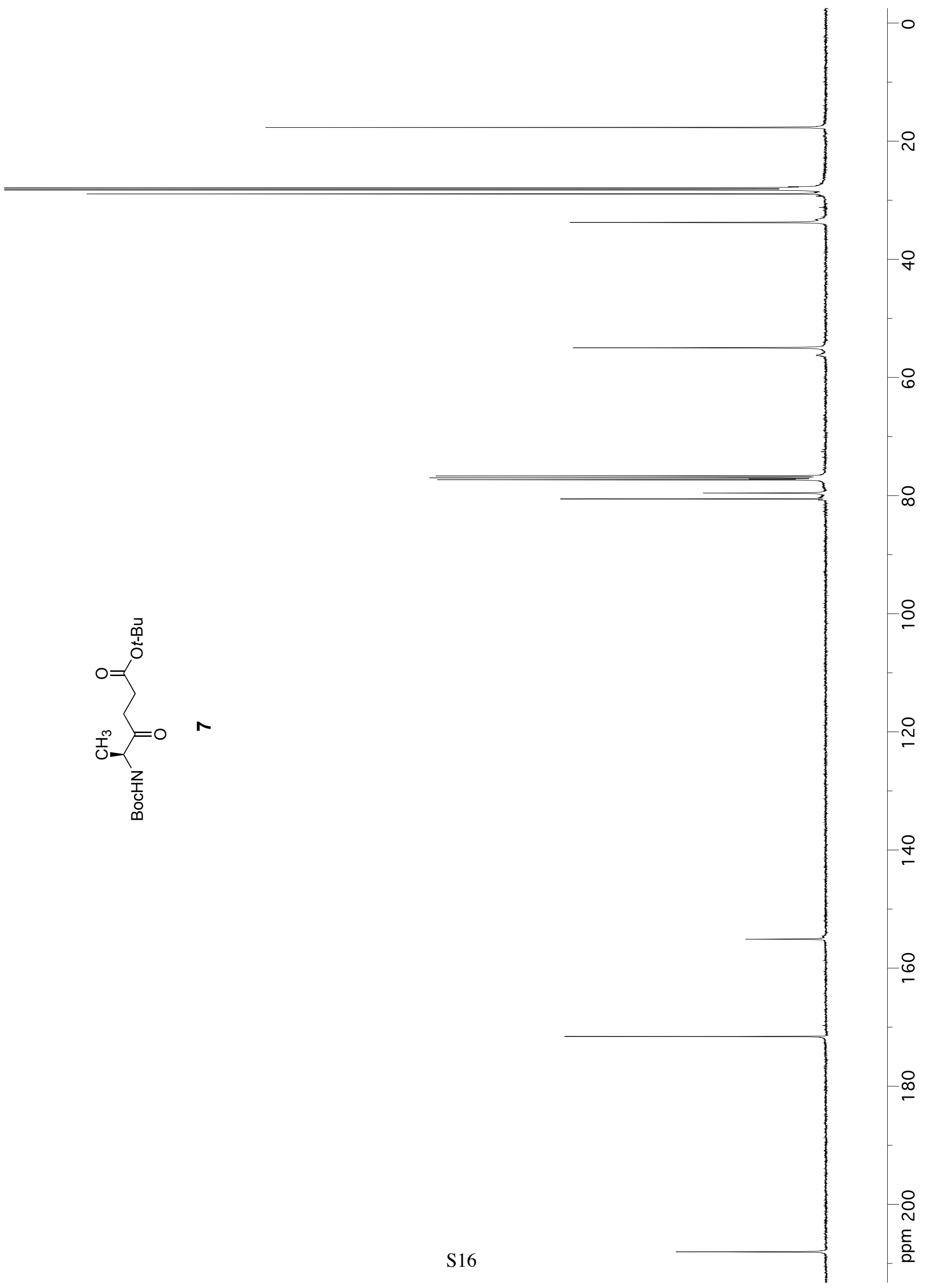




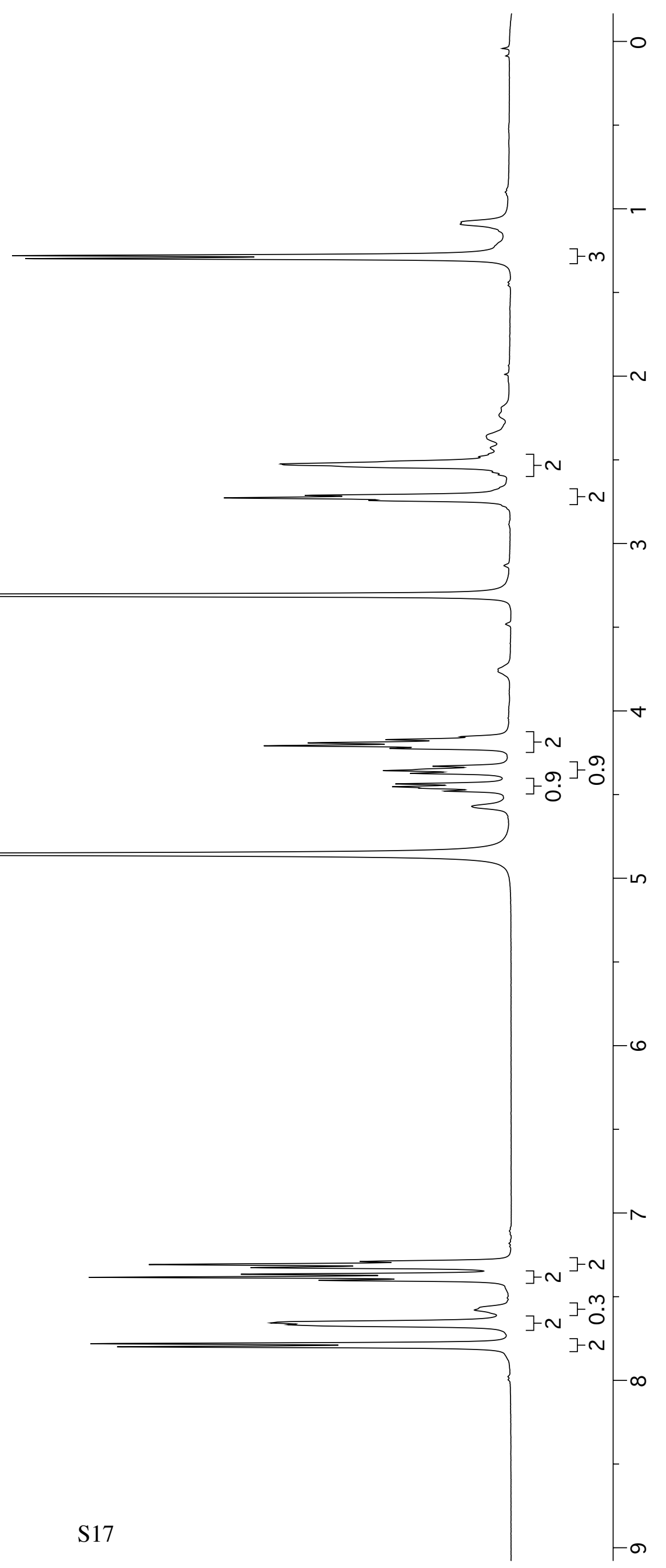




|




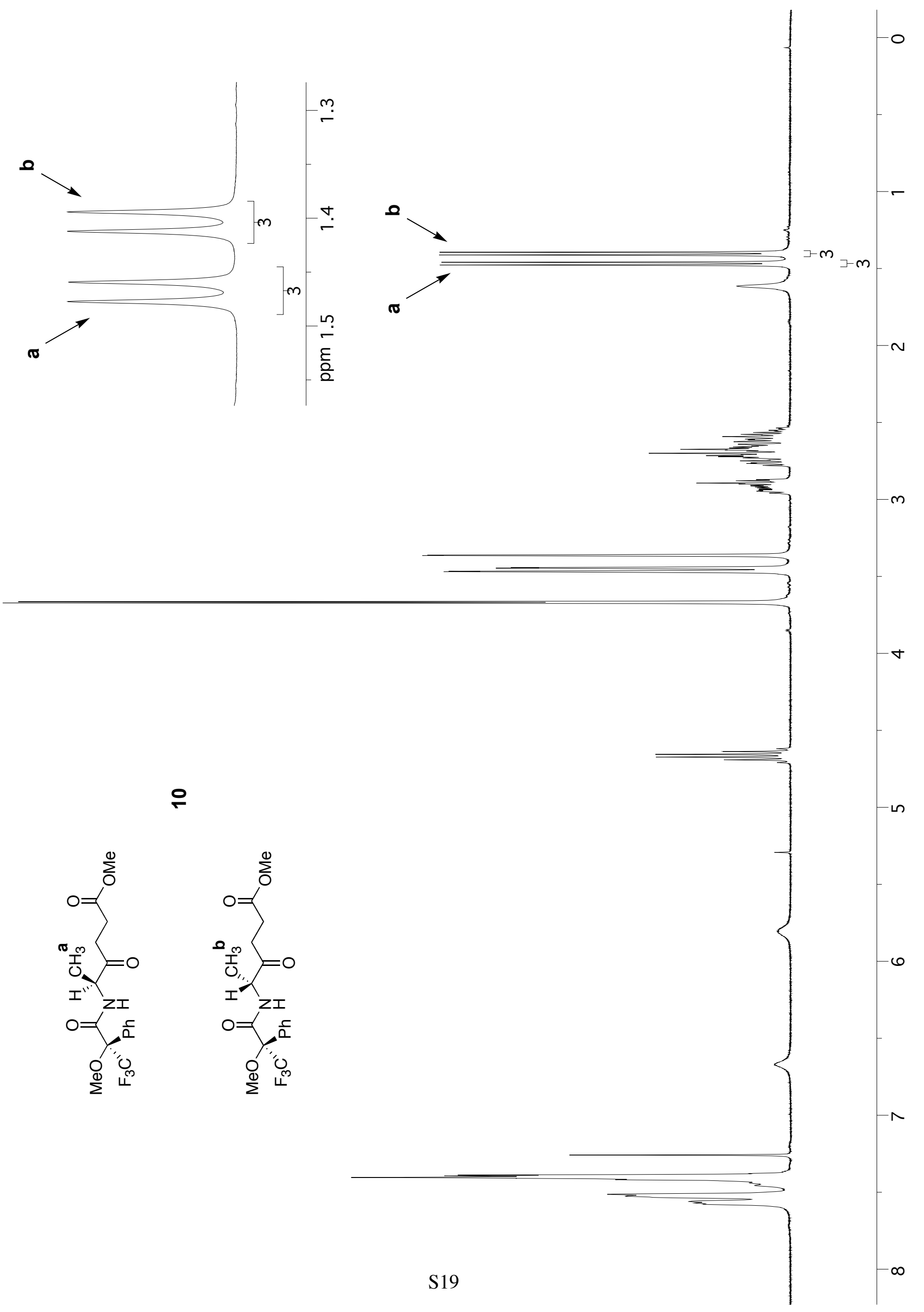




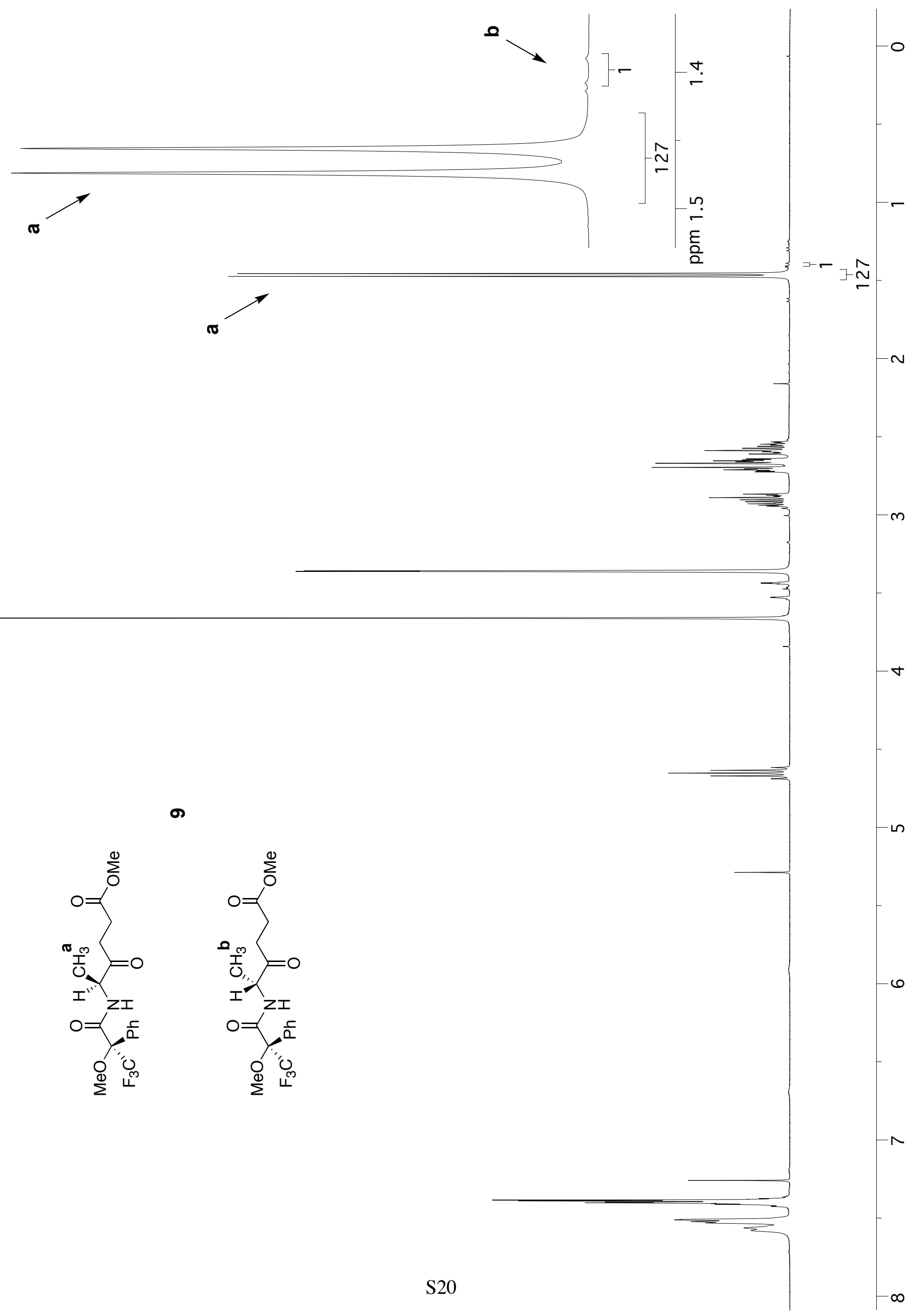




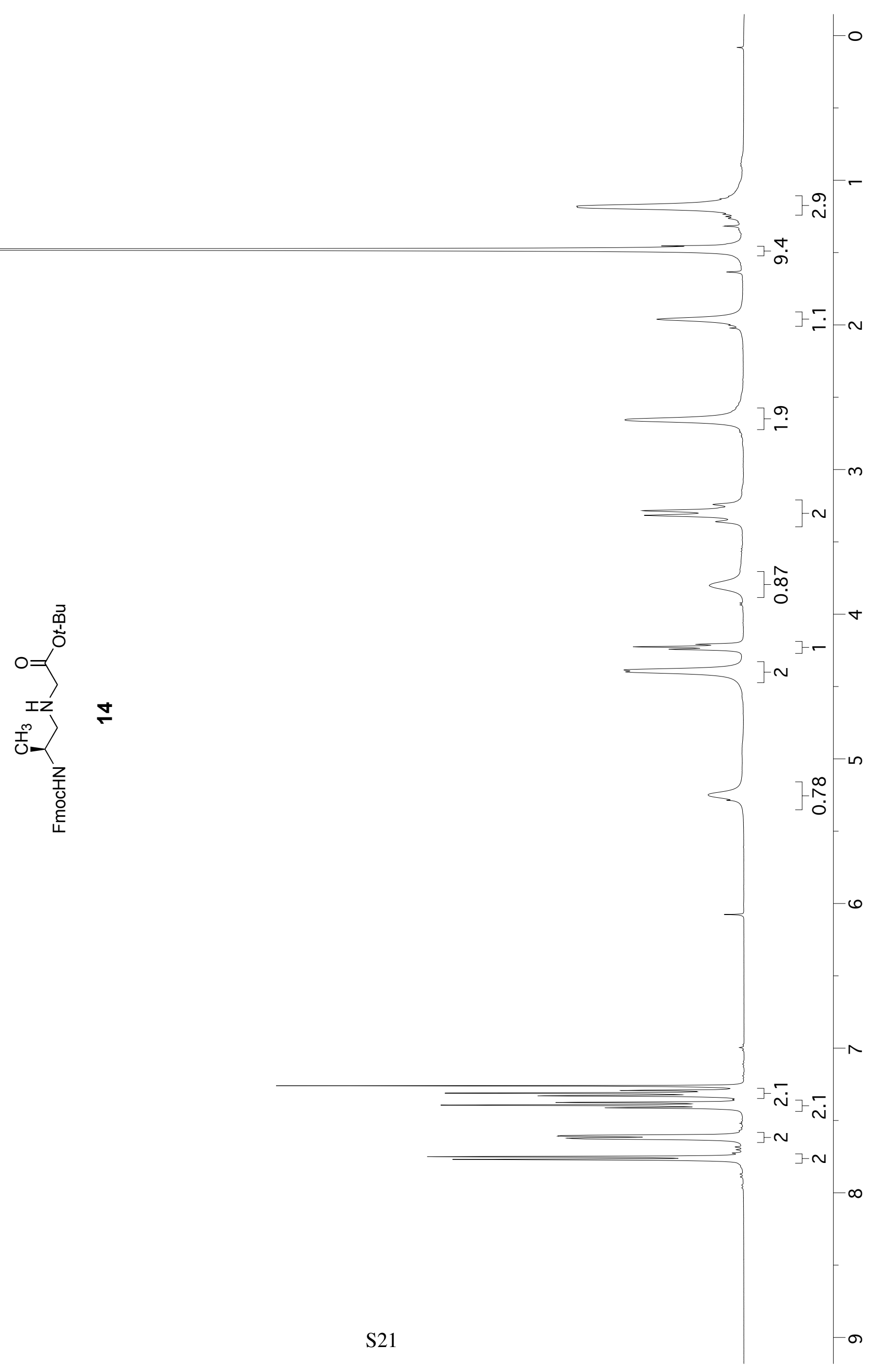




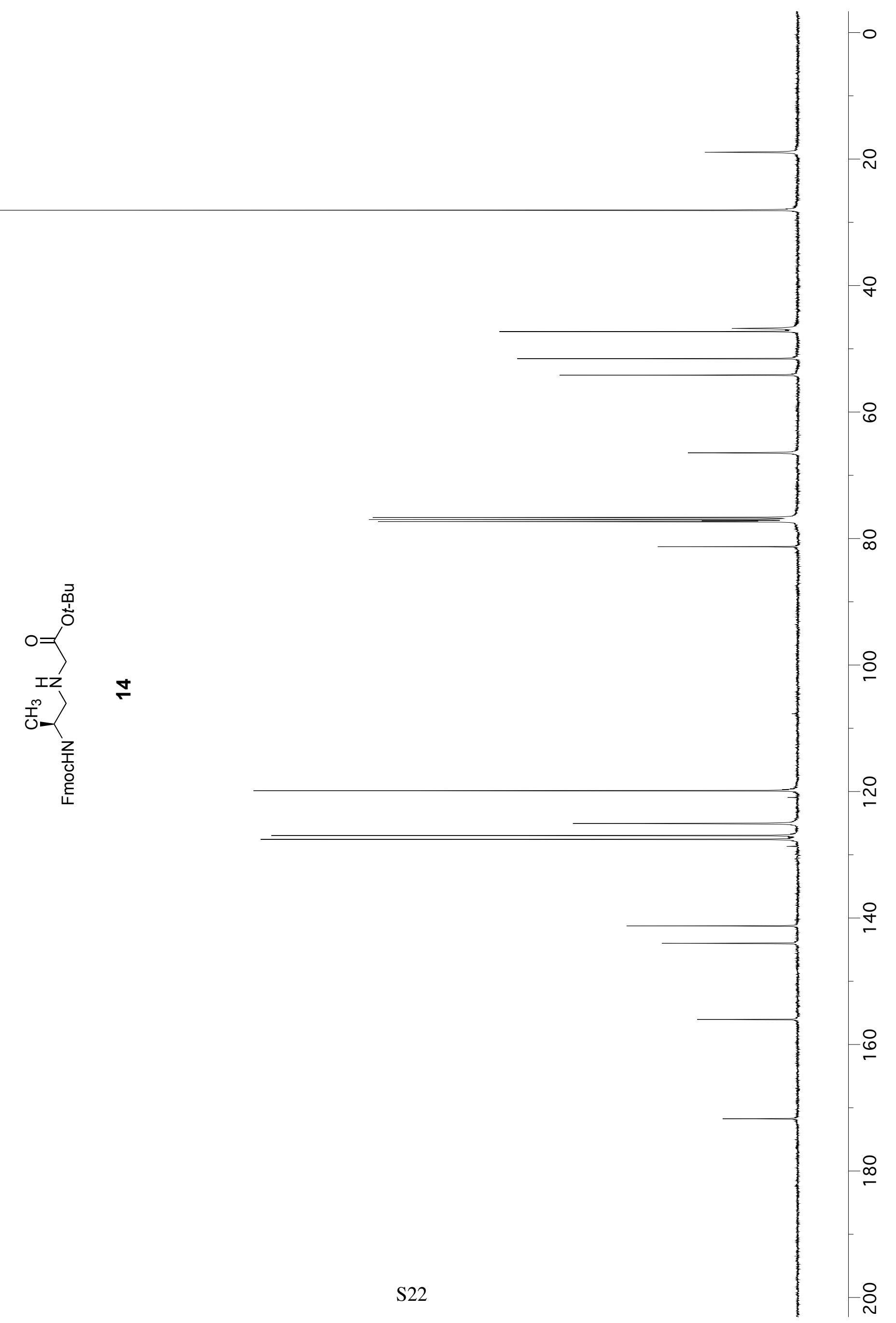




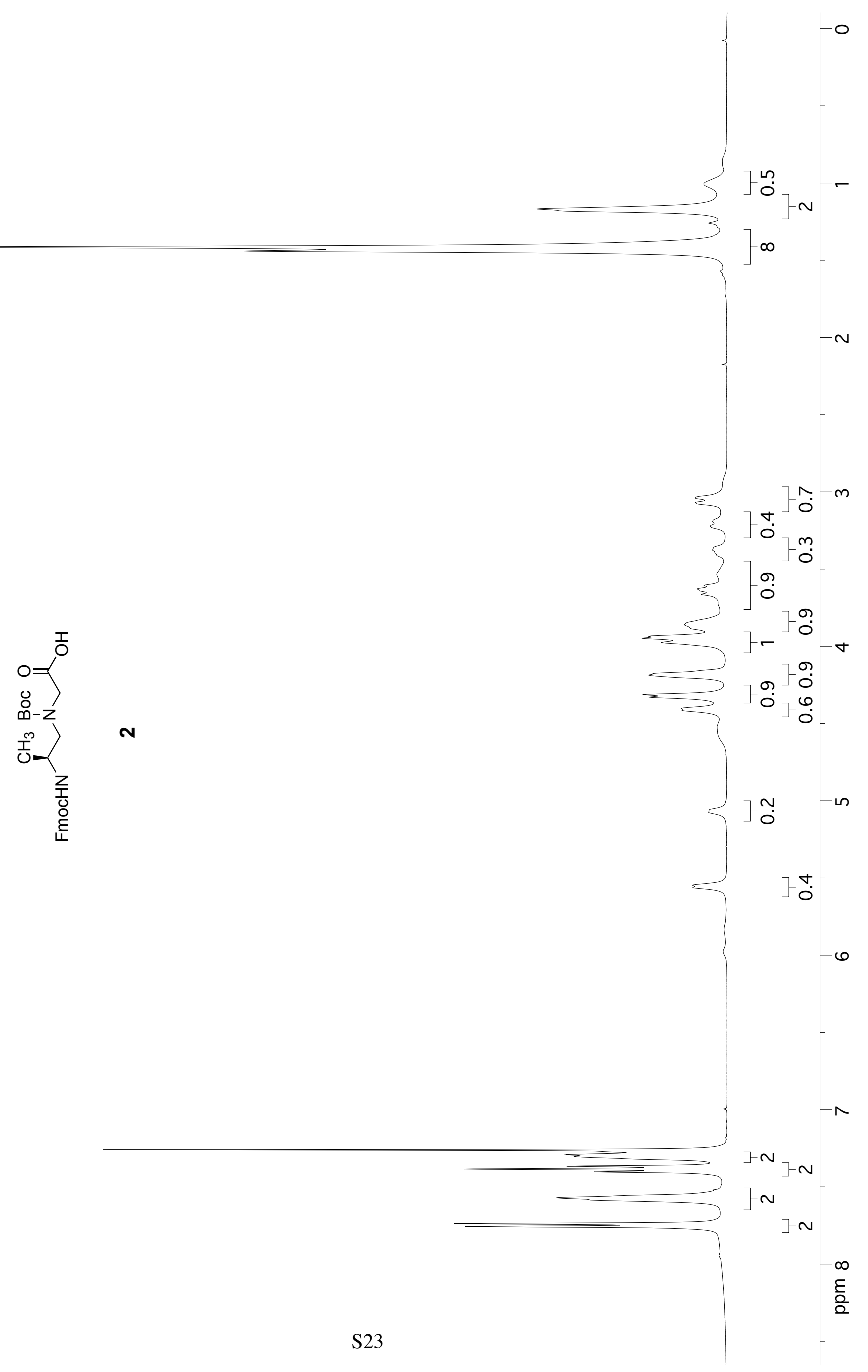




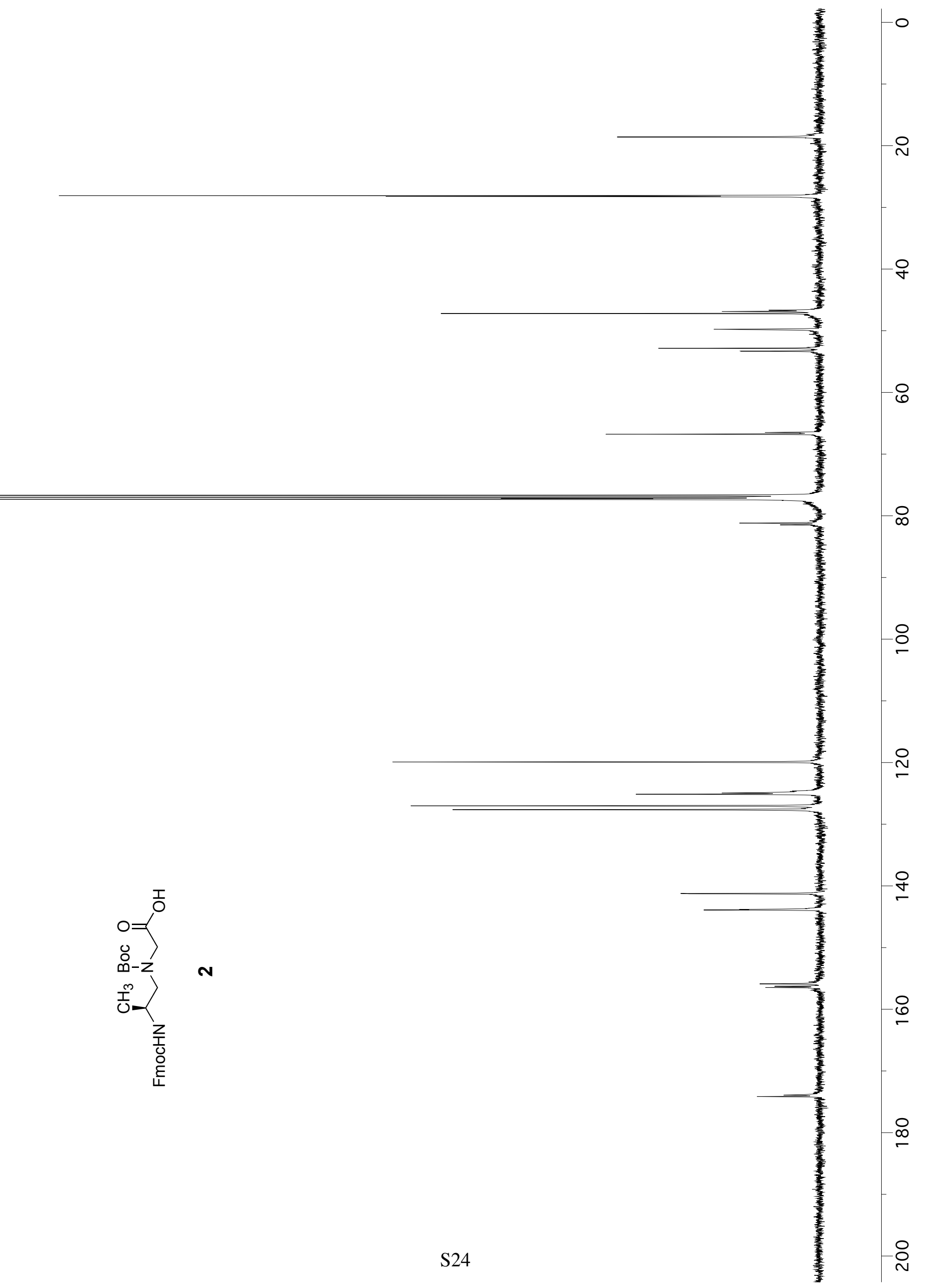




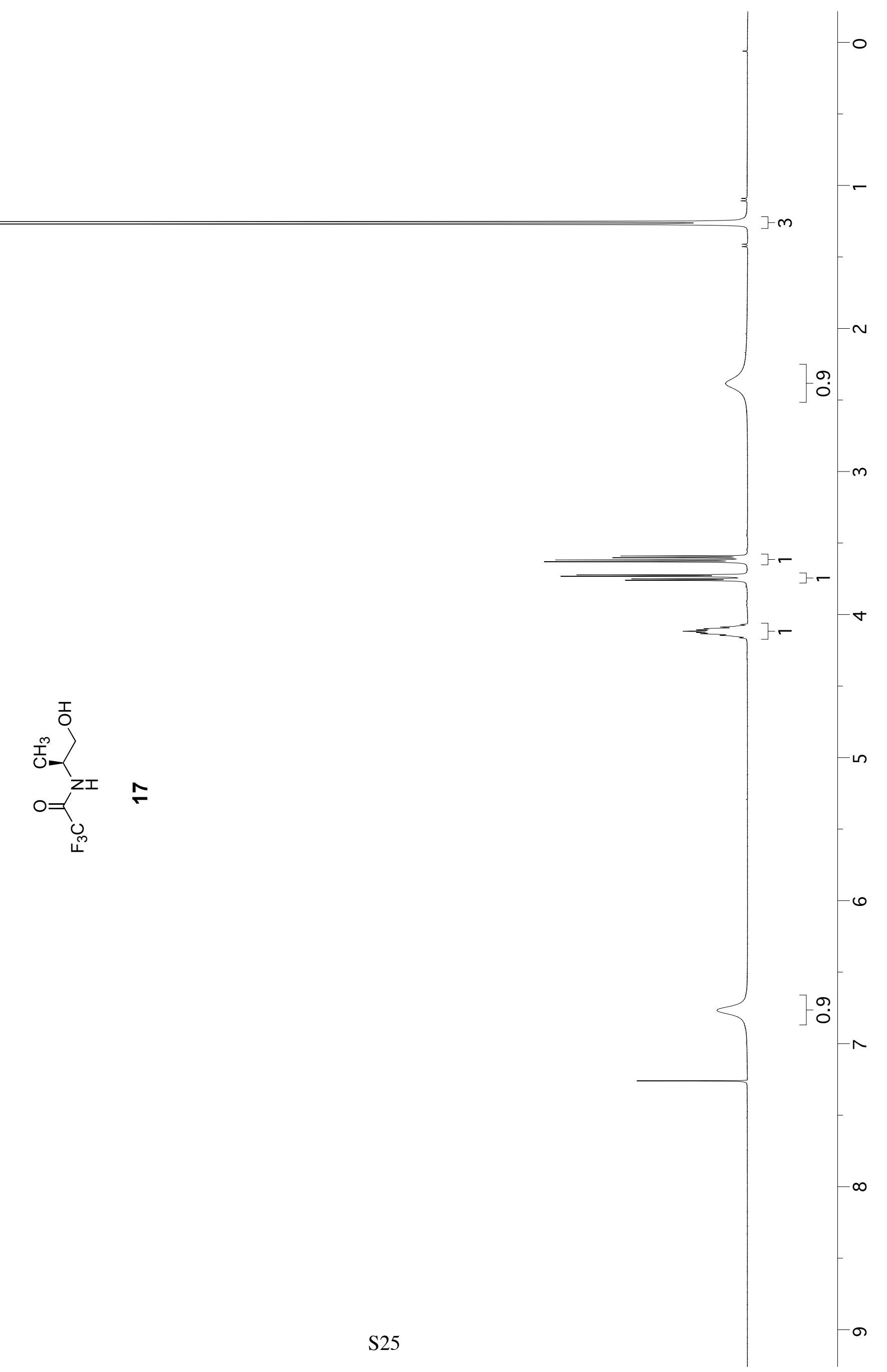




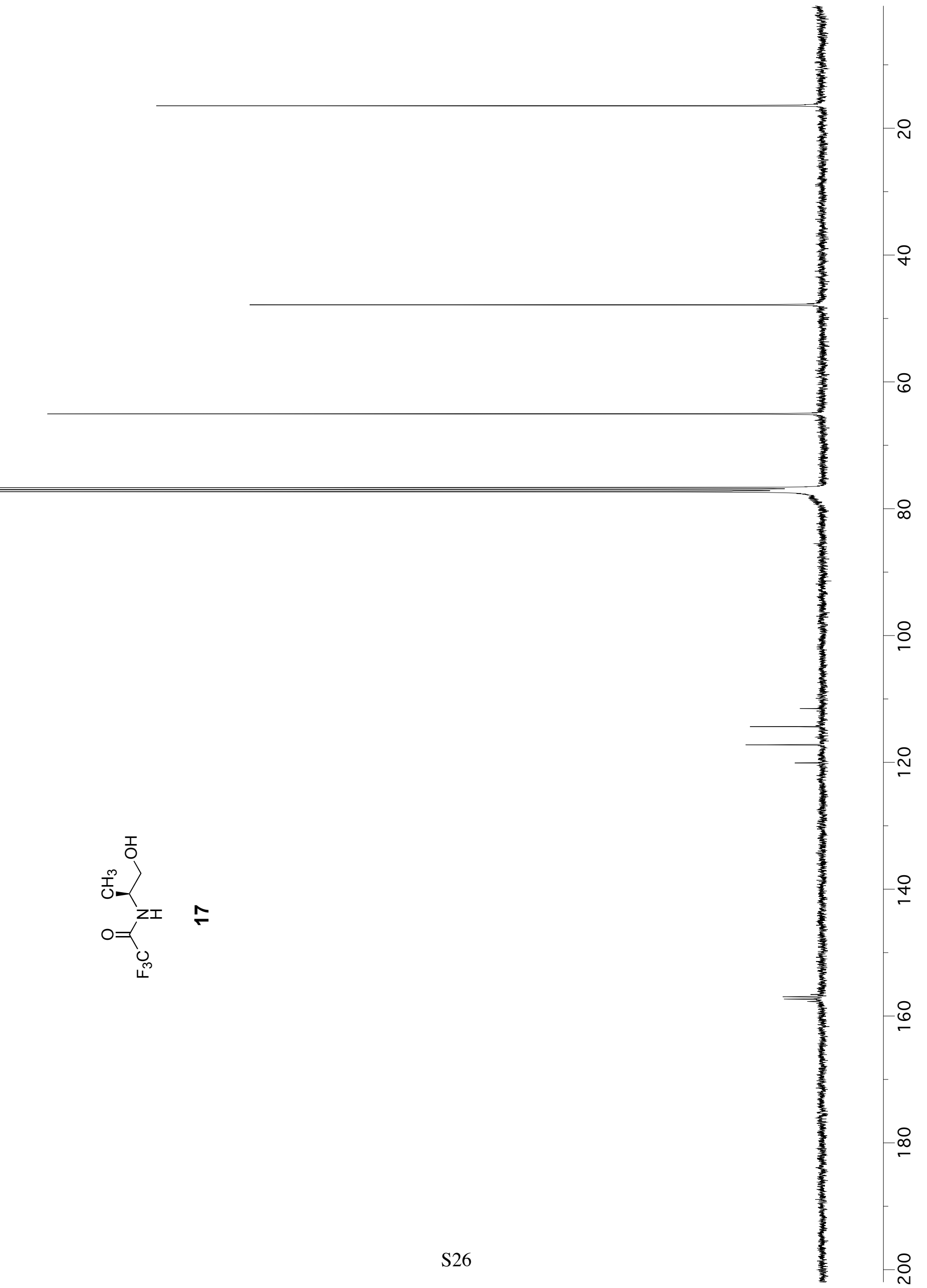




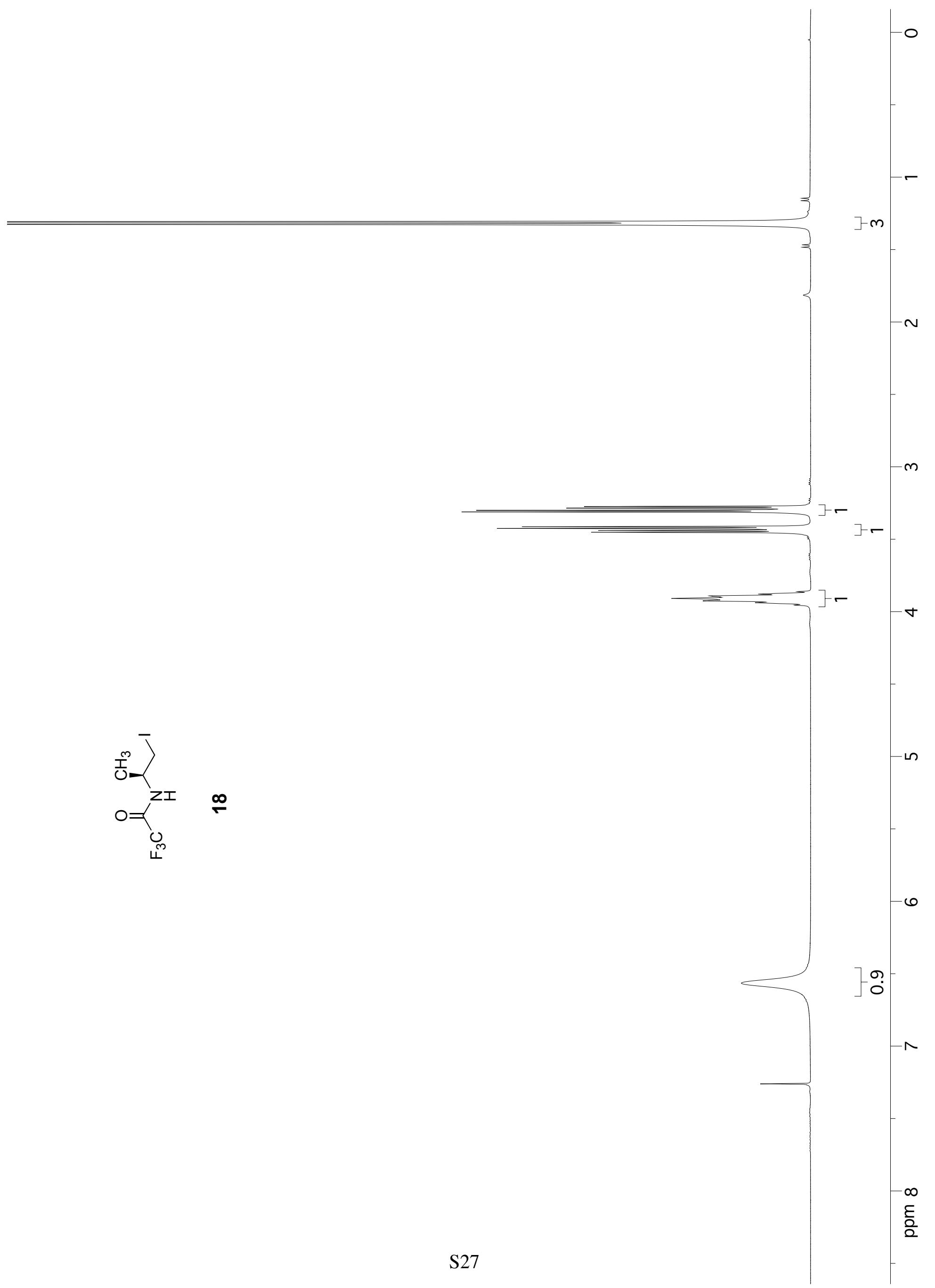




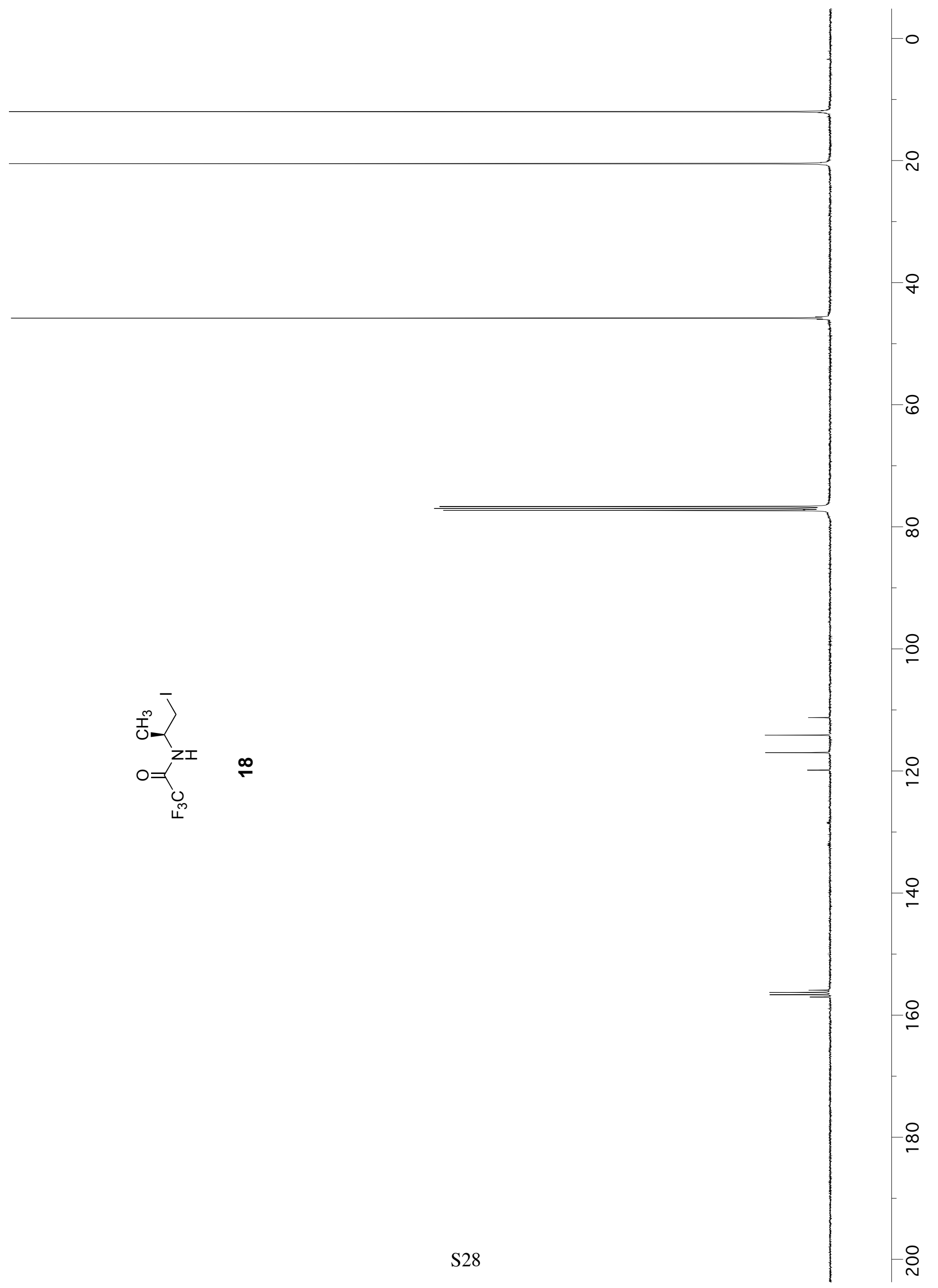



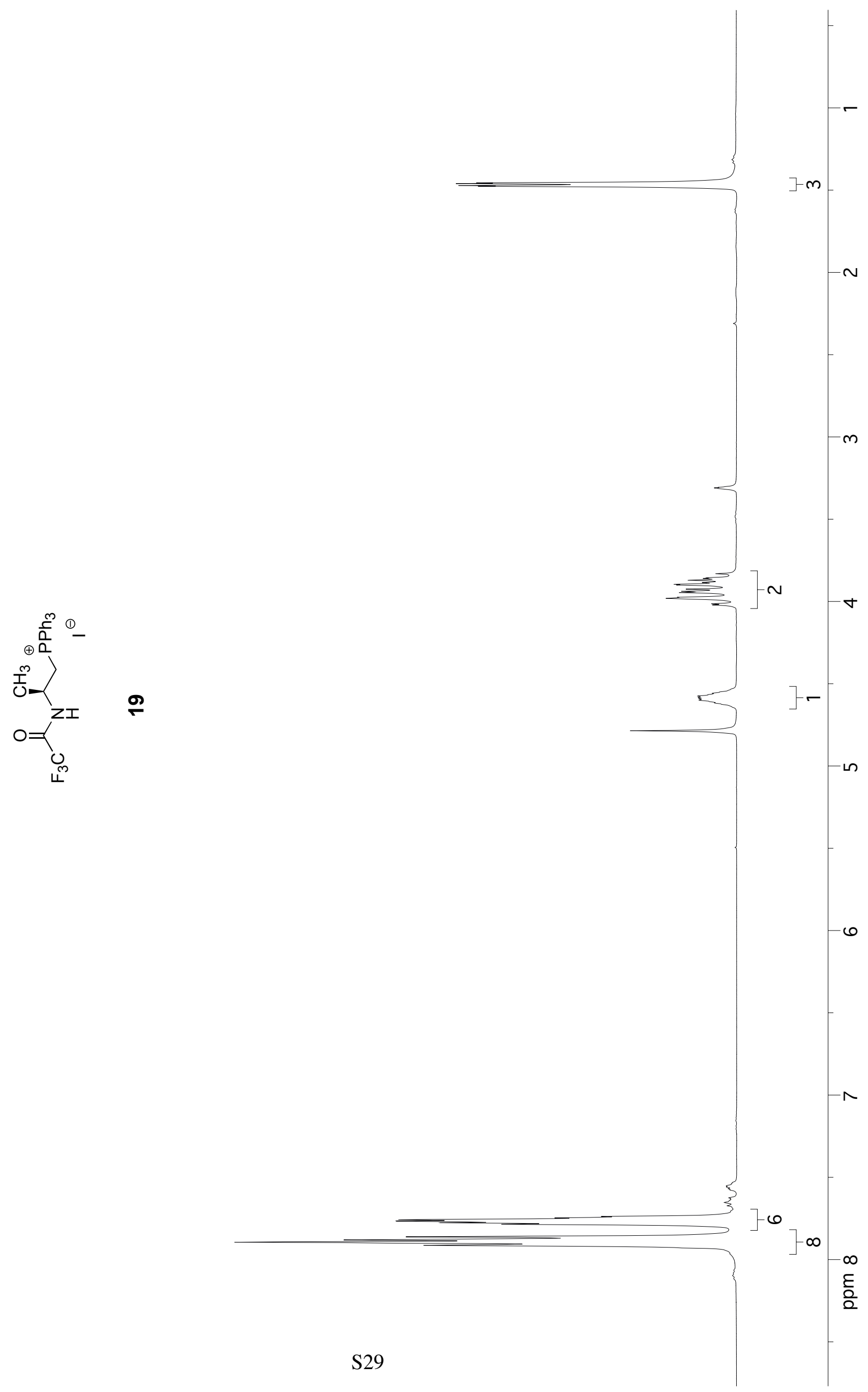

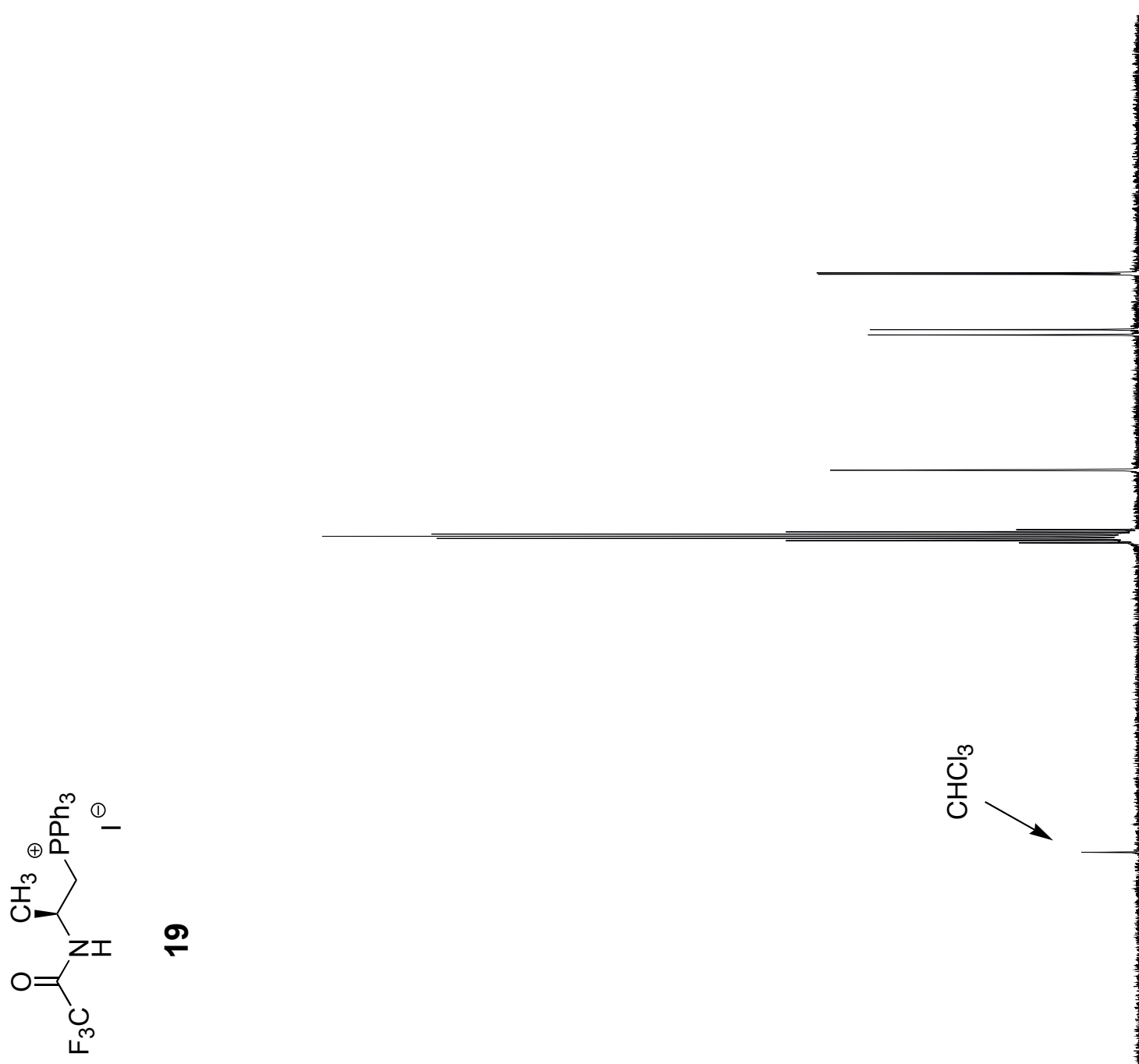

인

우

8

$\frac{m}{0}$

응

$\infty$

ㅁ

옴

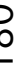




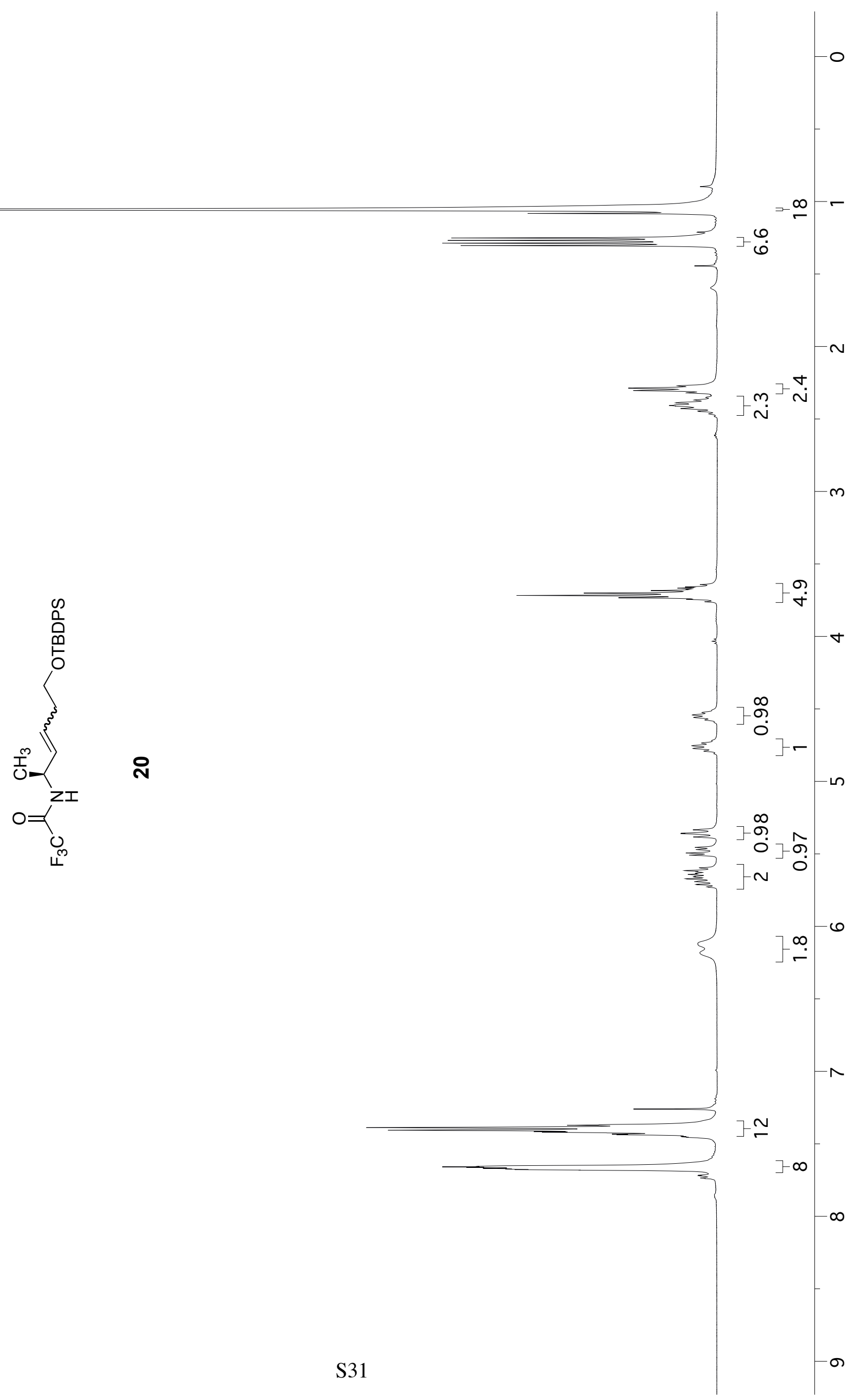




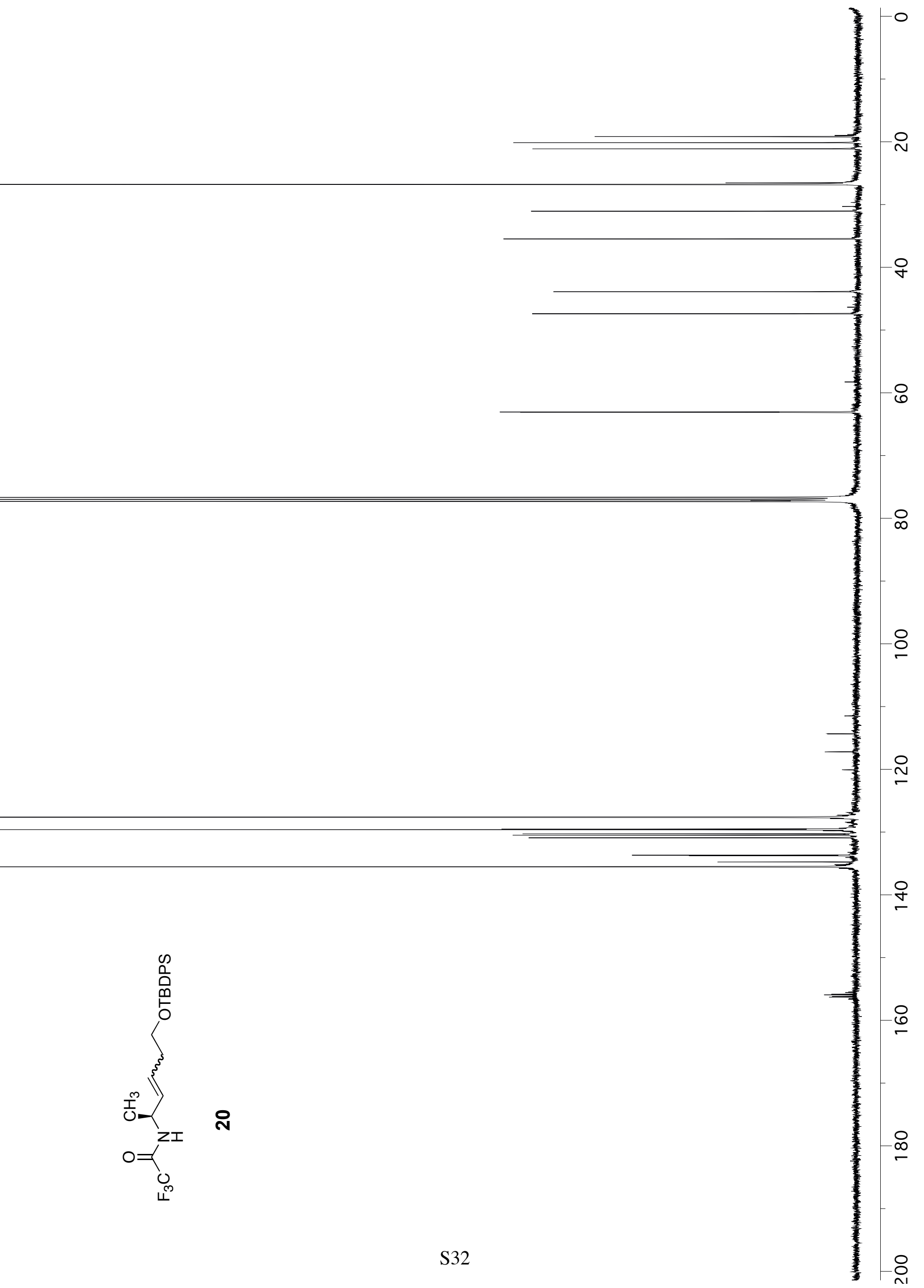




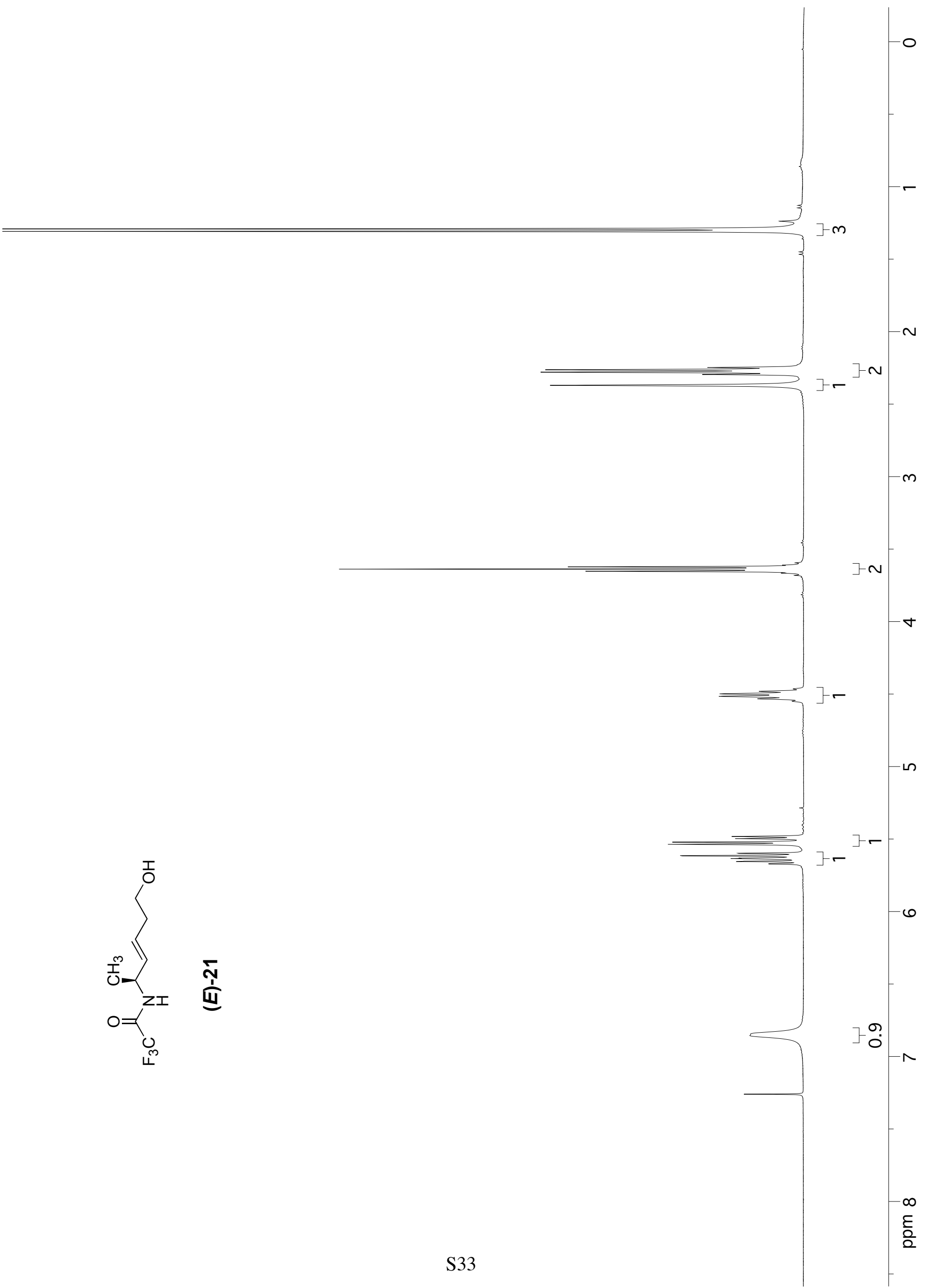




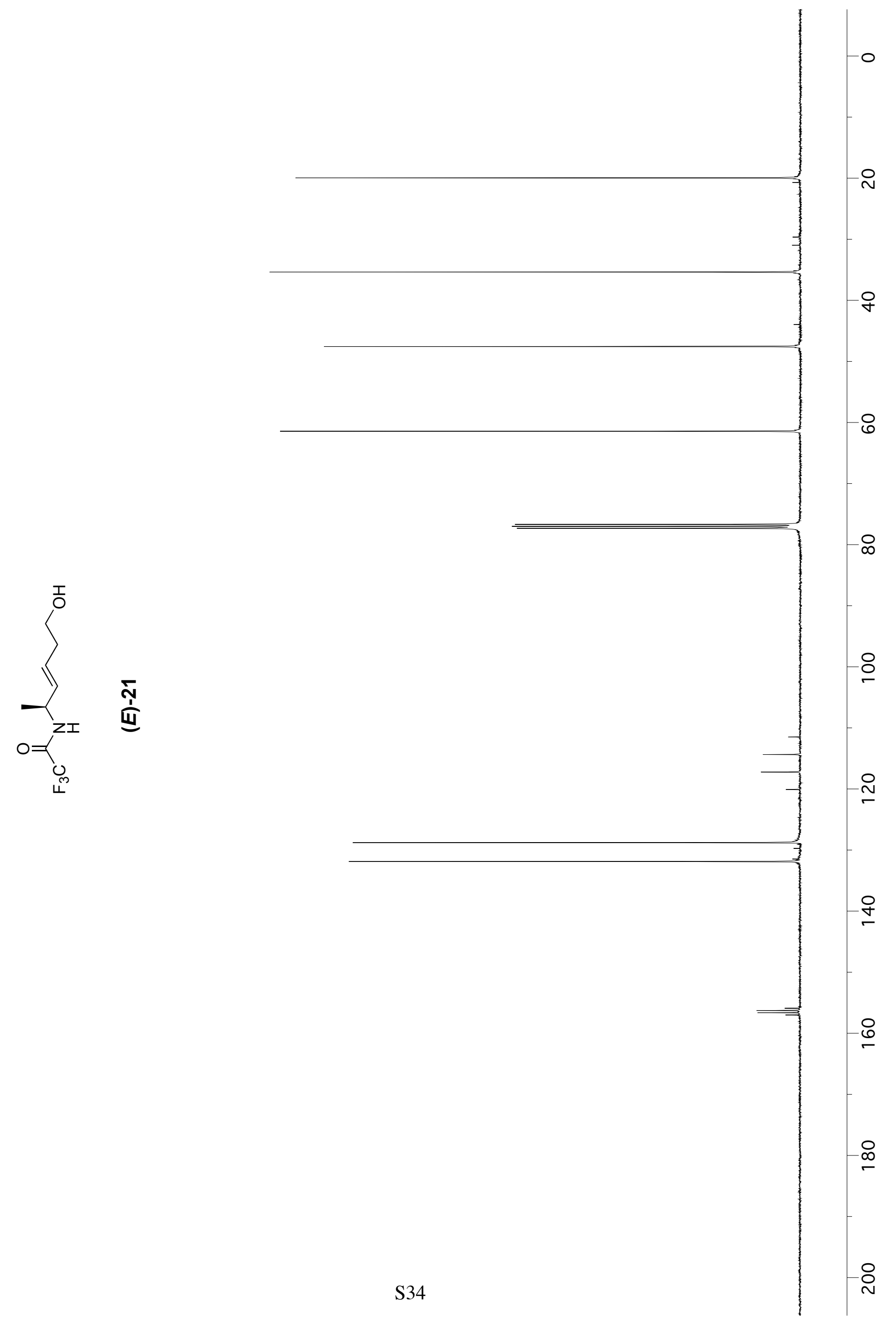




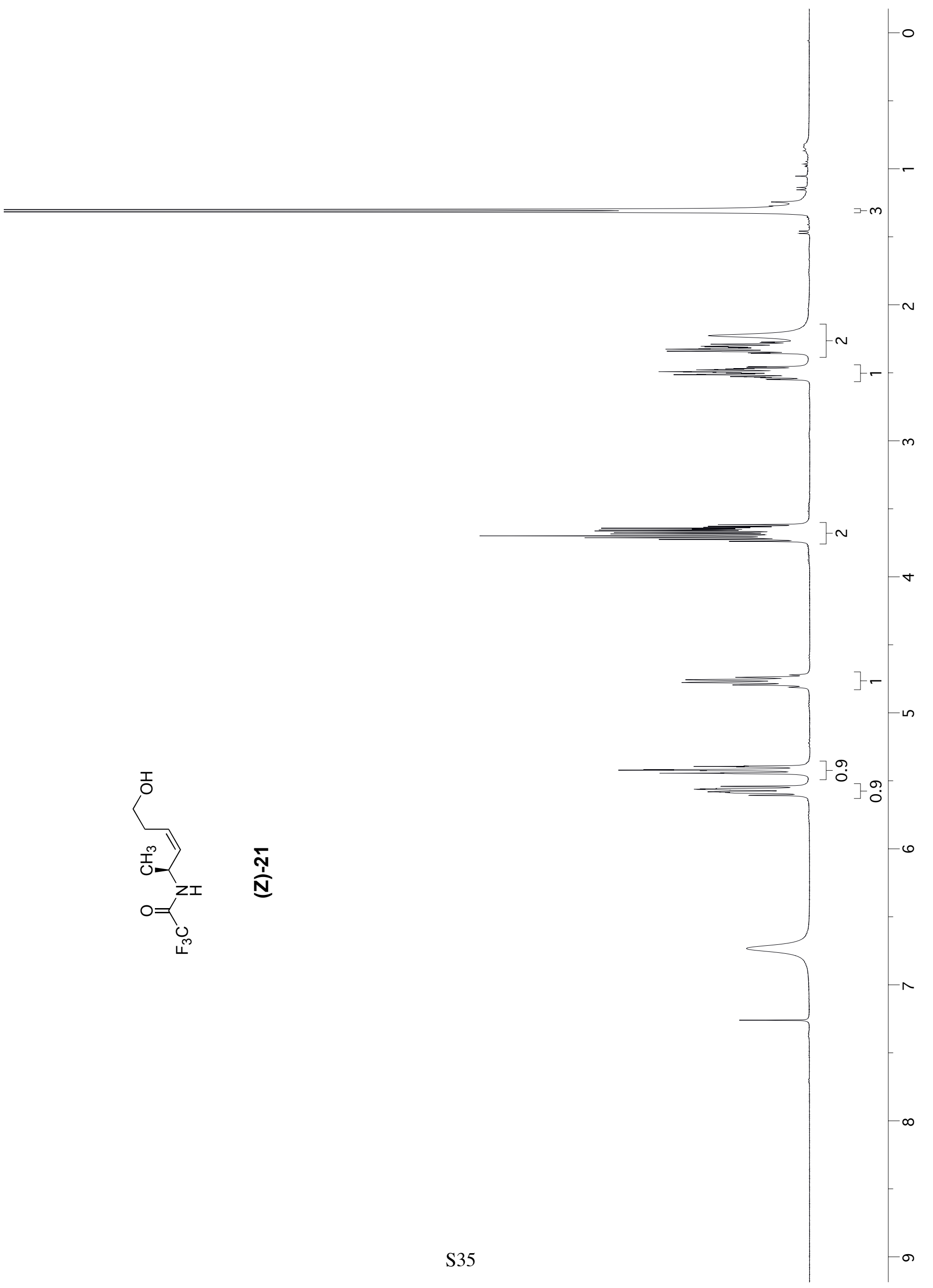




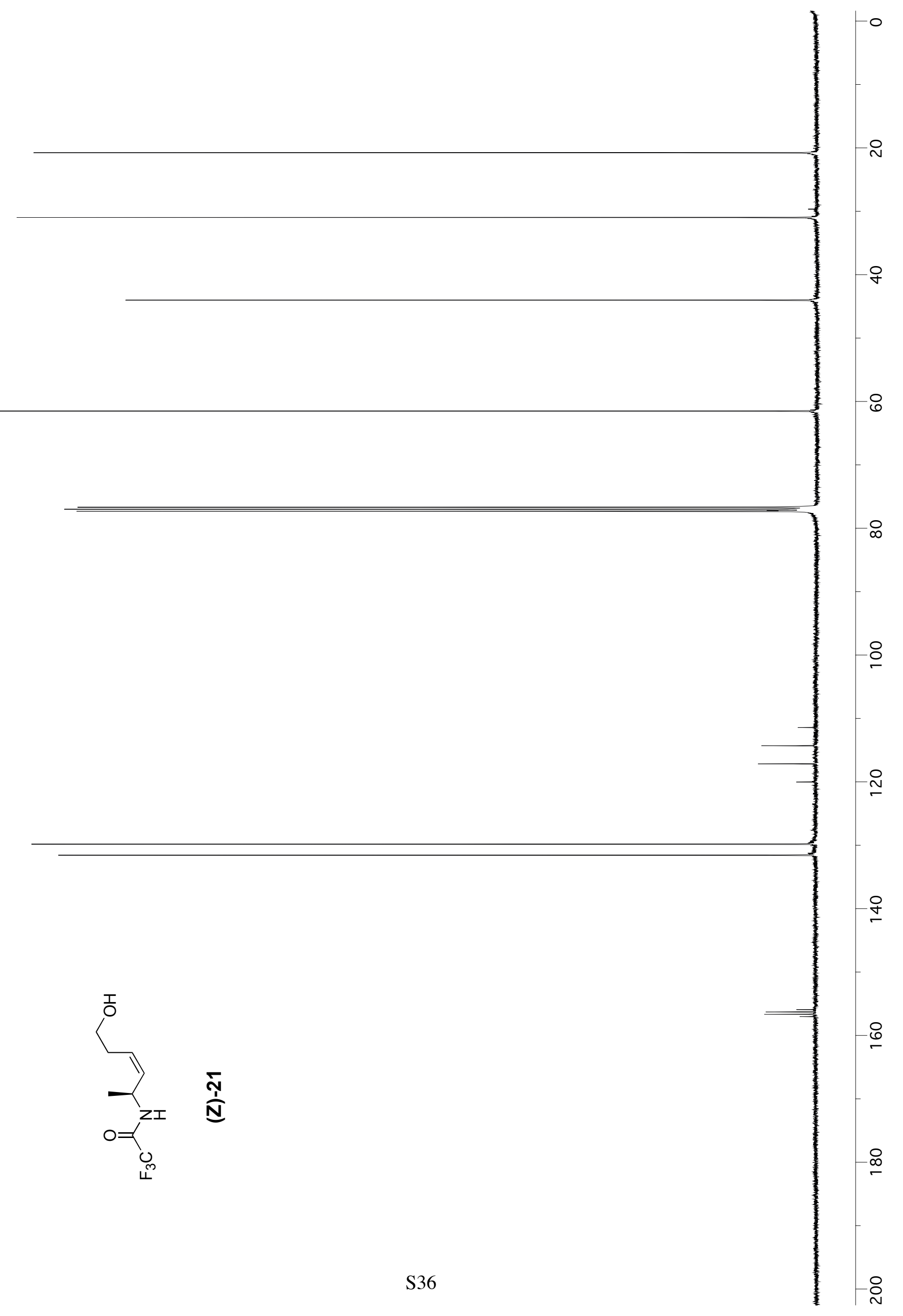




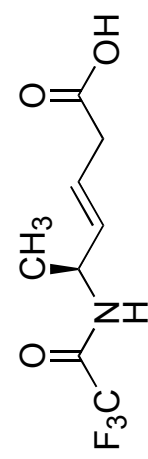

ก 


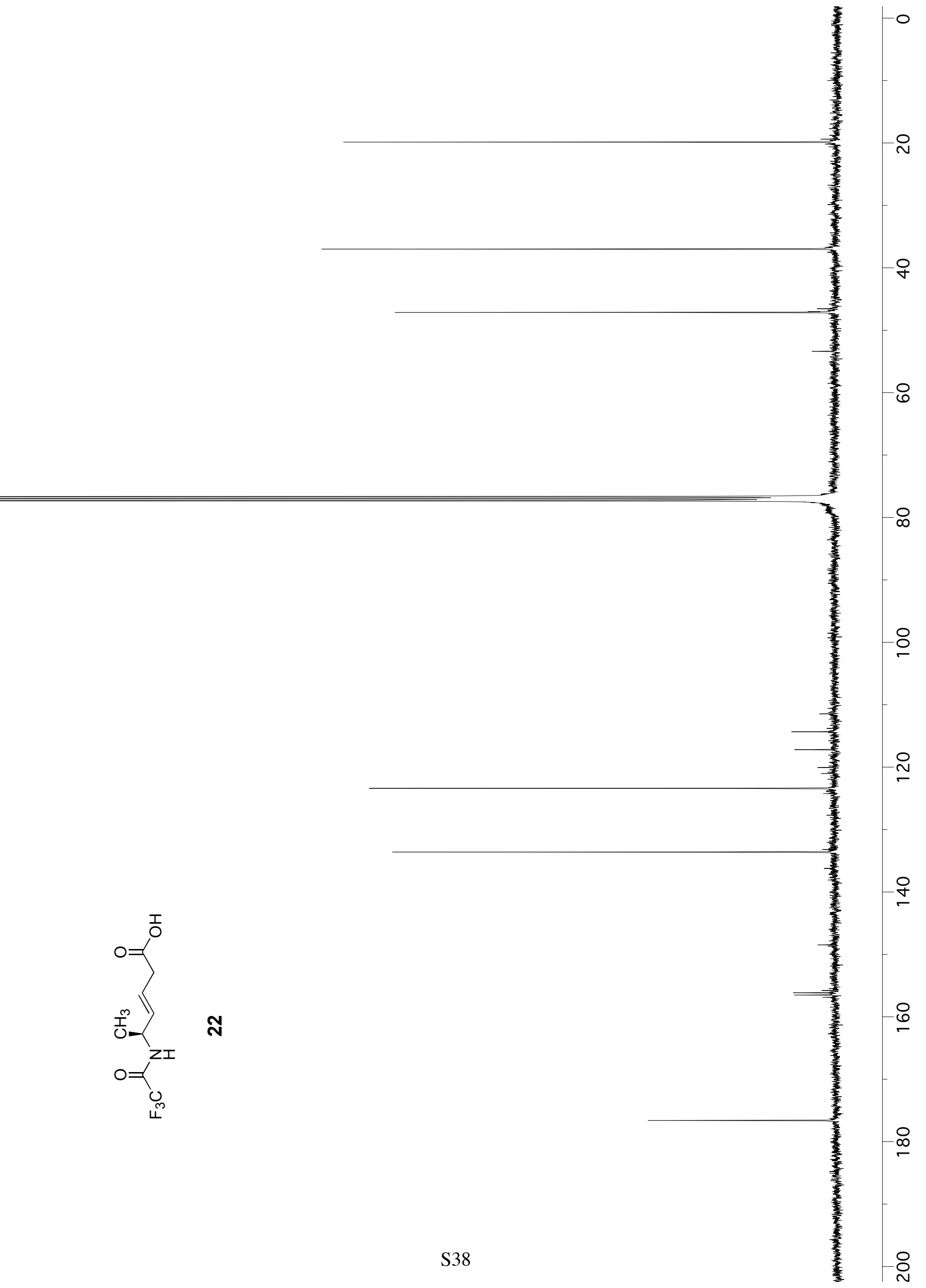




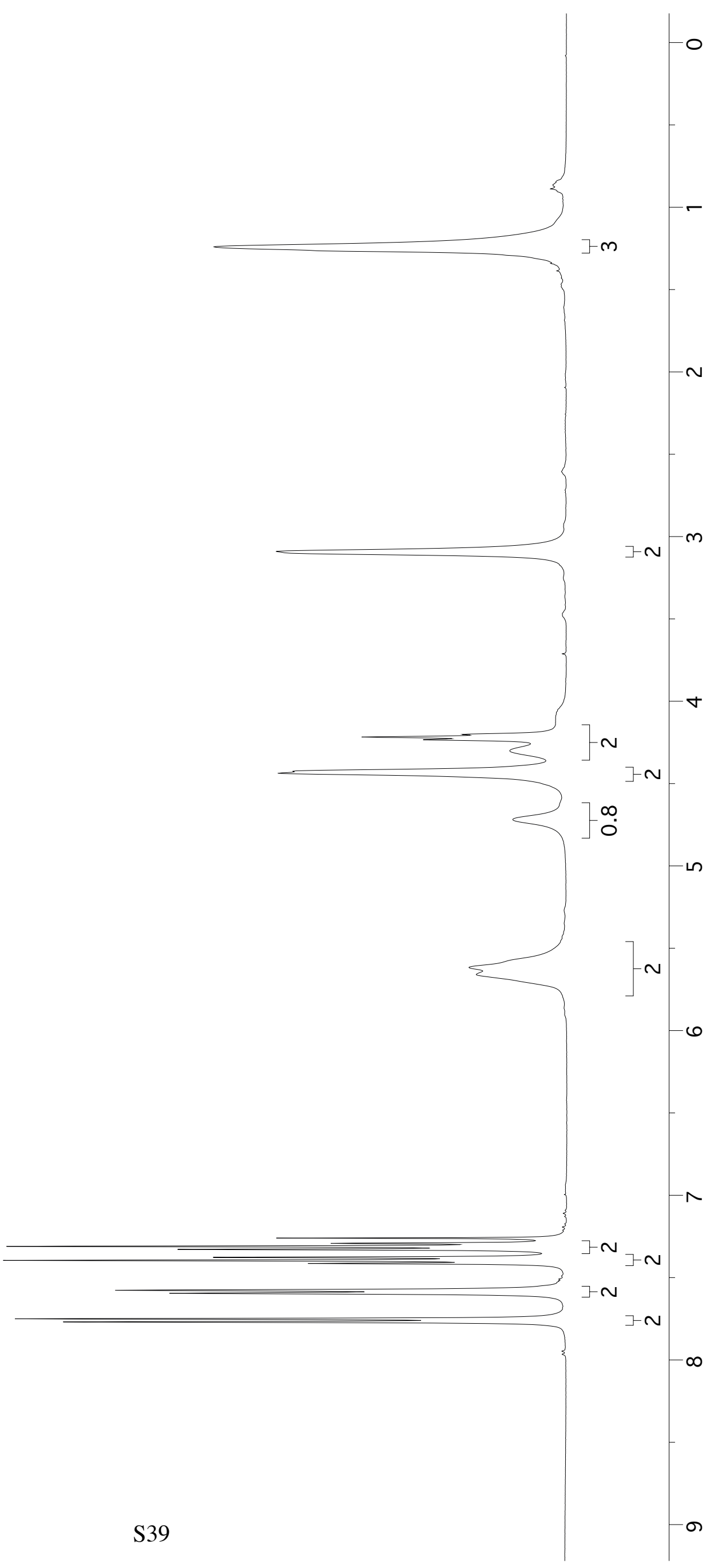




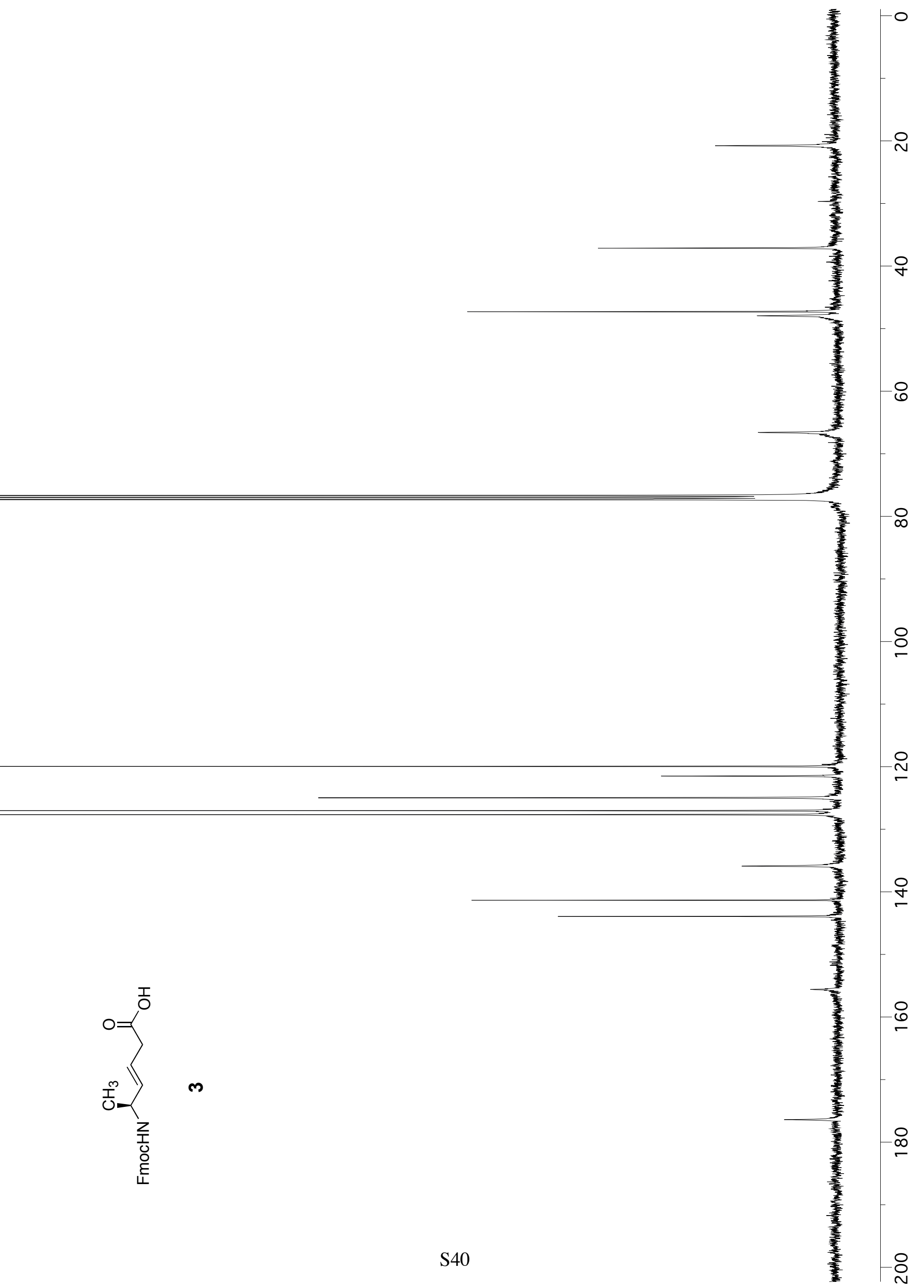




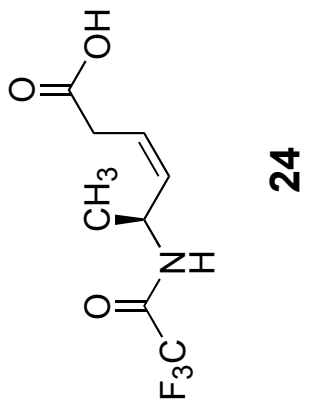




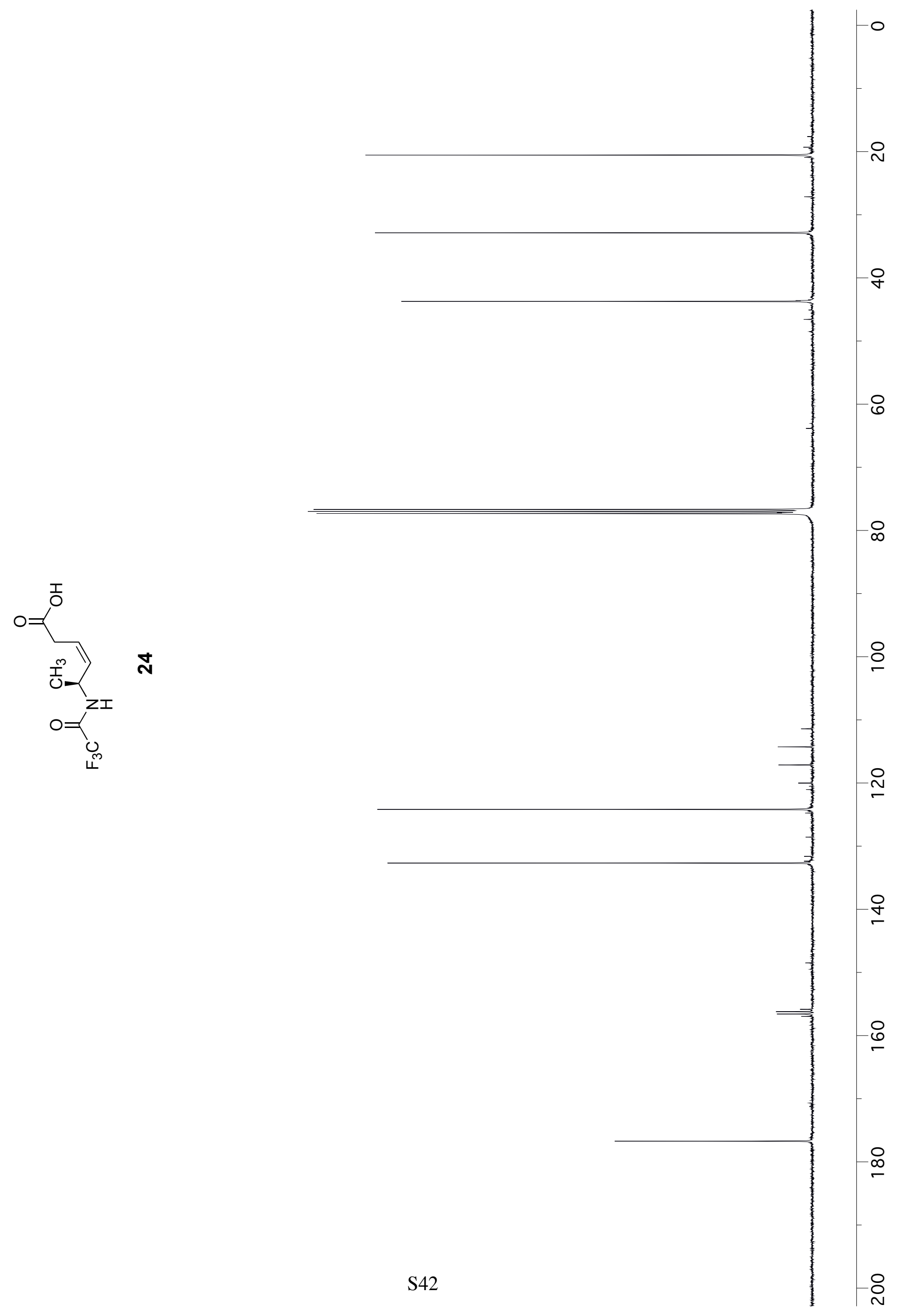



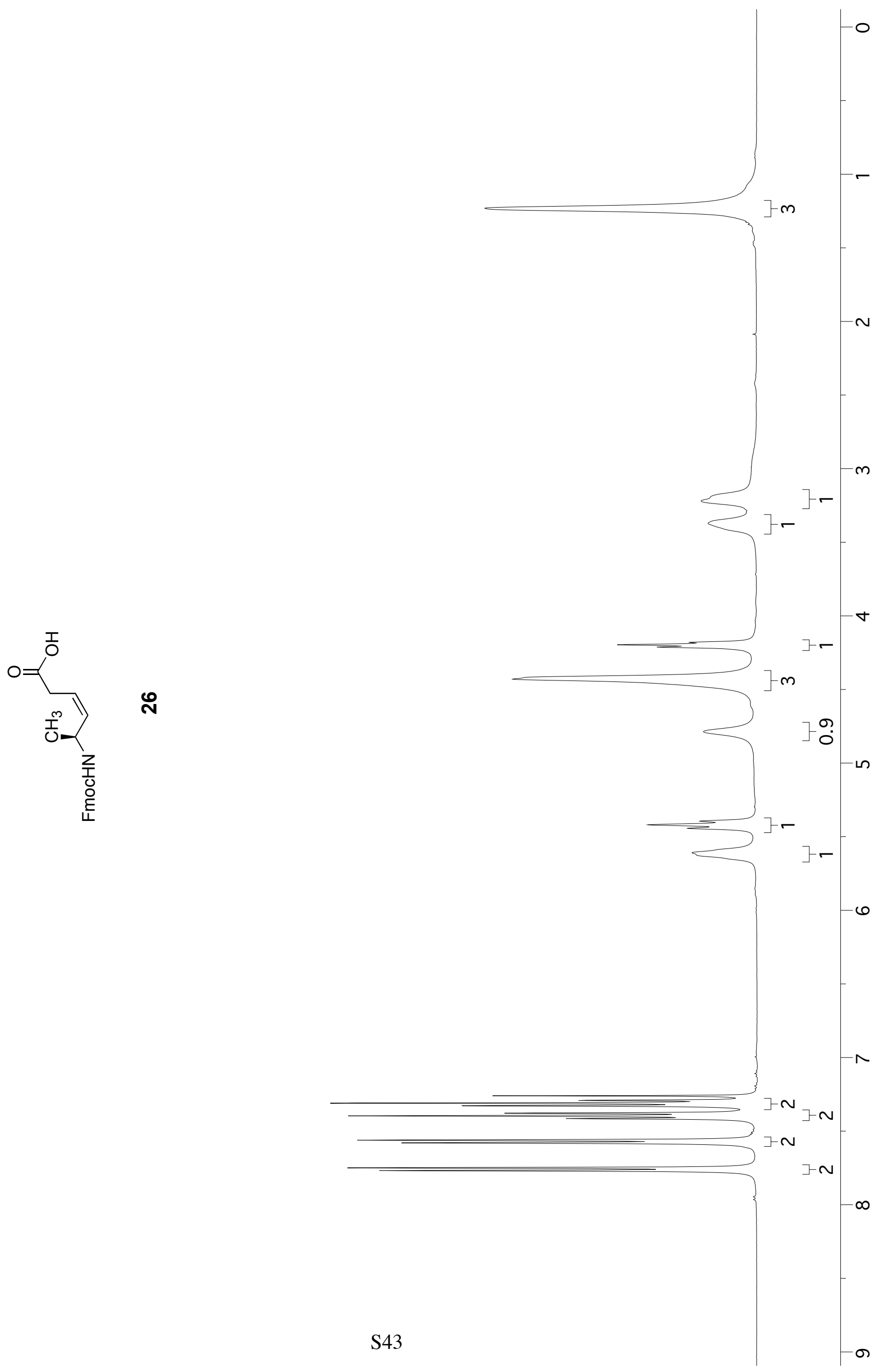


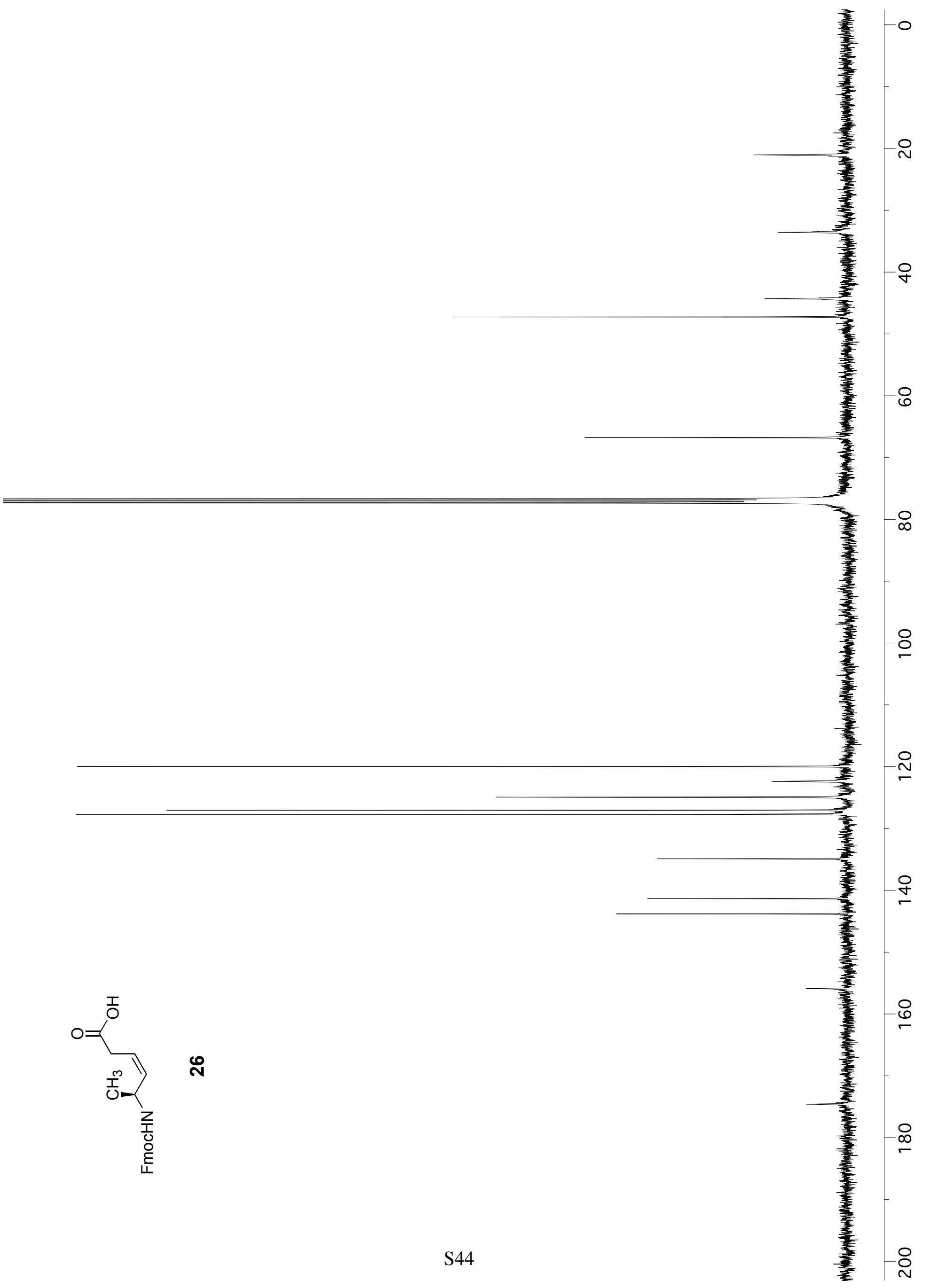

